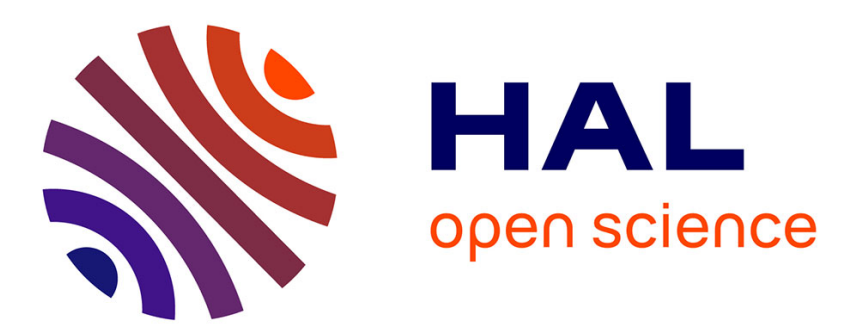

\title{
BMP-1 disrupts cell adhesion and enhances TGF- $\beta$ activation through cleavage of the matricellular protein thrombospondin-1
}

Cyril Anastasi, Patricia Rousselle, Maya Talantikite, Agnès Tessier, Caroline Cluzel, Alice Bachmann, Natacha Mariano, Mélissa Dussoyer, Lindsay

Alcaraz, Laëtitia Fortin, et al.

\section{To cite this version:}

Cyril Anastasi, Patricia Rousselle, Maya Talantikite, Agnès Tessier, Caroline Cluzel, et al.. BMP-1 disrupts cell adhesion and enhances TGF- $\beta$ activation through cleavage of the matricellular protein thrombospondin-1. Science Signaling, 2020, 13 (639), pp.eaba3880. 10.1126/scisignal.aba3880 . hal02991455

\section{HAL Id: hal-02991455 \\ https://hal.science/hal-02991455}

Submitted on 20 Nov 2020

HAL is a multi-disciplinary open access archive for the deposit and dissemination of scientific research documents, whether they are published or not. The documents may come from teaching and research institutions in France or abroad, or from public or private research centers.
L'archive ouverte pluridisciplinaire HAL, est destinée au dépôt et à la diffusion de documents scientifiques de niveau recherche, publiés ou non, émanant des établissements d'enseignement et de recherche français ou étrangers, des laboratoires publics ou privés. 


\section{BMP-1 disrupts cell adhesion and enhances TGF- $\beta$ activation through the cleavage of the matricellular protein thrombospondin-1}

Cyril Anastasi ${ }^{1, ¥}$, Patricia Rousselle $^{1, ¥}$, Maya Talantikite ${ }^{1}$, Agnès Tessier $^{1}$, Caroline Cluzel $^{1}$, Alice Bachmann ${ }^{1}$, Natacha Mariano $^{1}$, Mélissa Dussoyer ${ }^{1}$, Lindsay B. Alcaraz ${ }^{2, \S}$, Laëtitia Fortin $^{1}$, Alexandre Aubert ${ }^{1}$, Frédéric Delolme ${ }^{1,3}, \mathrm{Naïma} \mathrm{El}$ Kholti $^{1}$, Jean Armengaud ${ }^{4}$, Pierre Fournié ${ }^{5,6}$, Céline Auxenfans ${ }^{1,7}$, Ulrich Valcourt ${ }^{1,2}$, Sandrine Vadon-Le Goff ${ }^{1}$, Catherine Moali ${ }^{1, *}$

${ }^{1}$ University of Lyon, CNRS UMR5305, Tissue Biology and Therapeutic Engineering Laboratory (LBTI), F-69367 Lyon, France.

${ }^{2}$ University of Lyon, Centre Léon Bérard, INSERM U1052, CNRS UMR5286, Cancer Research Center of Lyon (CRCL), F-69373 Lyon, France.

${ }^{3}$ University of Lyon, ENS de Lyon, INSERM US8, CNRS UMS3444, SFR Biosciences, F-69366 Lyon, France

${ }^{4}$ CEA Marcoule, Innovative Technologies for Detection and Diagnostics Laboratory (DRF/Joliot/DMTS/SPI/Li2D), F30200 Bagnols-sur-Cèze, France

${ }^{5}$ Purpan University Hospital, Ophthalmology Department, F-31059 Toulouse, France

${ }^{6}$ University of Toulouse, CNRS UMR5165, INSERM U1056, Epithelial Differentiation and Rheumatoid Autoimmunity Unit (UDEAR), F-31059 Toulouse, France

${ }^{7}$ Hospices Civils de Lyon, Tissue and Cell Bank, F-69437 Lyon, France

${ }^{¥}$ These authors contributed equally.

*Corresponding author. Email: c.moali@ibcp.fr

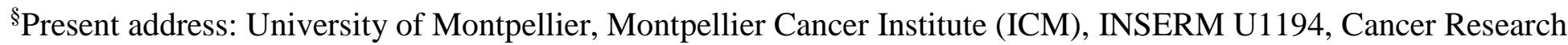
Institute of Montpellier (IRCM), F-34298 Montpellier, France. 


\section{ABSTRACT}

Bone morphogenetic protein 1 (BMP-1) is an important metalloproteinase that synchronizes growth factor activation with extracellular matrix assembly during morphogenesis and tissue repair. The mechanisms by which BMP-1 exerts these effects are highly context-dependent. Because it has been observed that BMP-1 overexpression induces marked phenotypic changes in two human cell lines (HT1080 and 293-EBNA cells), we investigated how BMP-1 simultaneously impacts cell-matrix interactions and growth factor activity in these cell lines. Increasing BMP-1 led to a loss of cell adhesion that depended on the matricellular glycoprotein thrombospondin-1 (TSP-1). BMP-1 cleaved TSP-1 between the VWFC/procollagen-like domain and the type 1 repeats that mediate several key TSP-1 functions. This cleavage induced the release of TSP-1 C-terminal domains from the extracellular matrix and abolished its previously described multi-site cooperative interactions with heparan-sulfate proteoglycan and CD36 on HT1080 cells. In addition, BMP-1-dependent proteolysis potentiated the TSP-1-mediated activation of latent transforming factor- $\beta$ (TGF- $\beta$ ), leading to increased signaling through the canonical SMAD pathway. In primary human corneal stromal cells (keratocytes), endogenous BMP-1 cleaved TSP-1, and the addition of exogenous BMP-1 enhanced cleavage, but this had no substantial effect on cell adhesion. Instead, processed TSP-1 promoted the differentiation of keratocytes into myofibroblasts and stimulated production of the myofibroblast marker $\alpha$-SMA, in agreement with the presence of processed TSP-1 in human corneal scars. Our results indicate that BMP-1 can both trigger the disruption of cell adhesion and stimulate TGF- $\beta$ signaling in TSP-1-rich microenvironments, which has important potential consequences for wound healing and tumor progression. 


\section{INTRODUCTION}

Bone morphogenetic protein-1 (BMP-1) and related proteinases belonging to the BTP (BMP-1/tolloid-like proteinases) family are recognized as key regulators of several developmental and physiological processes. Their crucial role in development was first established in Drosophila melanogaster and Xenopus laevis embryos, in which they directly control dorsoventral patterning $(1,2)$. This was further supported by knock-out studies in mice showing that deletion of the Bmpl or Tll1 (tolloid-like 1) gene leads to early lethality and is associated with developmental defects such as gut herniation (3) and abnormal septation and positioning of the heart (4). Mutations of the BMP1 gene in humans cause osteogenesis imperfecta (5), a bone disorder characterized by brittle bones that are prone to fracture. A similar phenotype is observed in adult mice upon Bmpl conditional ablation with the additional phenotypes of periodontal disease and skin fragility (6-8). In addition, BTPs are known to be involved in the control of muscle growth and homeostasis (9) and in wound healing and tissue repair $(6,10)$. Finally, several pathological conditions seem to involve increased BMP-1 abundance, including osteoarthritis (11), heart fibrosis (12-14), pelvic organ prolapse (15), corneal scarring (10), keloids (16), and type 1 diabetes (17). BMP-1 is also reported to belong to a group of signature extracellular matrix (ECM) proteins associated with the high metastatic potential of breast tumors (18), and its increased abundance correlates with high grade tumors and/or poor survival prognosis in several types of cancers (19-21).

BMP-1 is a member of the astacin subgroup of metzincin metalloproteinases (22). The latent pro form of the proteinase is processed in the secretory pathway to yield the mature enzyme, which is composed of a catalytic domain followed by three CUB (complement, uEGF, BMP-1) domains and one EGF (epidermal growth factor) domain. The non-catalytic domains also play a major, though indirect, role in enzyme activity by regulating substrate access to the active site and processing $(23,24)$. More than thirty BMP-1 substrates have been identified and characterized biochemically (reviewed in $(25,26))$. An important group of substrates consists of ECM precursor proteins that acquire the ability to form threedimensional networks upon proteolytic maturation. Well-known examples are procollagens I-III, which can form fibers after C-terminal propeptide removal by BTPs to provide the principal scaffolding component of most connective tissues. Other prominent BMP-1 substrates belonging to this group are minor fibrillar procollagens (V and XI), small leucine-rich 
proteoglycans (decorin, osteoglycin, and biglycan), basement membrane components (laminin 332 and collagen VII), and mineralization factors (dentin matrix protein 1 and dentin sialophosphoprotein).

The second major group of substrates consists of latent forms of growth factors and cytokines or antagonists that sequester these ligands, which, upon cleavage, result in increased signaling activities. The first substrate in this group to be described was chordin, a major antagonist of BMP-2 and BMP-4 during development $(2,27)$. Also, the latent forms of growth differentiation factor-11 (GDF-11, (28)) and of the inhibitor of muscle growth GDF-8 (also known as myostatin, (9)) as well as insulin-like growth factor-binding protein 3 (IGFBP3), which can bind and sequester IGF-I and II (29), can be cleaved by BMP-1 to release the active growth factors. A natural ligand of myostatin (WFIKKN1) was also found to behave as both a substrate of BMP-1 and a positive regulator of BMP-1-dependent myostatin activation (30), and three proteins involved in the control of transforming growth factor $\beta$ (TGF- $\beta$ ) activity [latent TGF- $\beta$ binding protein-1 (LTBP1), TGF- $\beta$ receptor III, and CD109] have been shown to be under the proteolytic control of BMP-1 $(31,32)$. Finally, BMP-1 is also considered as a major player in lipid metabolism by mediating the maturation of apolipoprotein A1, the processing of the LDL receptor, and the release of the endotrophin adipokine from the C-terminus of the $\alpha 3$ chain of collagen VI (33-35).

Additionally, several potential BMP-1 substrates identified in a proteomic screen (31) are still awaiting validation, suggesting that the substrate repertoire of the proteinase is still not fully characterized and that many new functions remain to be discovered. However, linking the phenotype of Bmpl-deficient animals and disease mechanisms to this large panel of substrates remains challenging, because most BMP-1 activities are strongly contextual and interconnected. In the present study, we investigated the striking de-adhesion phenotype induced by BMP-1 overexpression in two human cell lines and revealed that this was mainly due to the cleavage of thrombospondin-1 (TSP-1), an ECM protein classified as "matricellular" for its ability to regulate cell-matrix interactions. Further, we showed that the BMP-1-mediated cleavage of TSP-1 enhanced its ability to activate TGF- $\beta$ and to promote the differentiation of primary human keratocytes into myofibroblasts, both in 2D cultures and in an ex vivo model of corneal wound healing. 


\section{RESULTS}

\section{BMP-1 disrupts cell adhesion in 293-EBNA and HT1080 cells}

293-EBNA cells, a variant of human embryonic kidney HEK293 cells, have been widely used to produce recombinant BMP-1 (36-38). However, when these cells are grown to high density while producing BMP-1, they detach from culture plates en masse in the form of cell-cell adherent sheets (Fig. 1, A and B; fig. S1A). This can be avoided by using plates coated with poly-D-lysine (37), but the mechanism underlying this observation has remained unclear. As a first step to elucidate the BMP-1-induced loss of adhesion, we added the synthetic BMP-1 inhibitor S33A (a hydroxamate inhibitor referred to as hxt in this study $(31,39))$ to the culture medium and observed that the BMP-1-producing cells could be efficiently maintained in the adherent state in the presence of the inhibitor (Fig. 1A). This was the first indication that the loss of adhesion involved the catalytic activity of BMP-1. We also observed that the secreted, active form of BMP-1 was present both in the cell supernatant and the ECM of 293-EBNA cells (Fig. 1C).

To determine if the loss of cell adhesion was a general property of BMP-1-transfected cells, we also transfected a construct encoding BMP-1 into the human fibrosarcoma cell line HT1080 to produce HT1080-BMP-1 cells (31). We used cells transfected with a construct encoding the catalytically inactive E94A mutant form of BMP-1 (HT1080-E94A; (31)) in parallel as a control. The adhesion of HT1080 cells also seemed to depend on the presence of active BMP-1 because HT1080-BMP-1 cells, but not HT1080-E94A cells, lost their ability to adhere when grown to high cell densities. In contrast to 293-EBNA cells, however, the loss of adhesion in HT1080 cells was preceded by striking modifications in cell morphology that became more pronounced as the cell density increased, as evidenced through phase contrast imaging, time-lapse microscopy, and actin staining (Fig. 1, D and E; movies S1 and S2). The determination of the mean cell area after actin staining revealed a significant decrease in HT1080-BMP-1 cell size before detachment (Fig. 1F). None of these modifications were observed in HT1080-E94A cells, which behaved very much like parental HT1080 cells. Moreover, addition of exogenous sizzled, a Xenopus protein that specifically inhibits BMP-1 activity (40, 41), to HT1080-BMP-1 cells inhibited both morphological changes and cell detachment (Fig. 1D). We therefore concluded that in two different 
cell lines, HT1080 and 293-EBNA cells, BMP-1 induced a loss of cell adhesion in a manner that depended on the catalytic activity of the proteinase.

Finally, we used flow cytometry to determine if cell detachment could be a consequence of cell apoptosis by sorting cells labelled with an antibody recognizing annexin $\mathrm{V}$ and propidium iodide, which label apoptotic and dead cells respectively. At the two cell densities that were analyzed (20\% and $50 \%$ ), we found that apoptotic cells represented less than $3 \%$ of the total cell population and that cell viability was more than $94 \%$ for all three HT1080 cell types (fig. S1B). These results demonstrate that apoptosis was not a major determinant of the observed changes in cell adhesion.

\section{The adhesion phenotype observed in HT1080-BMP-1 cells is due to changes in the ECM}

To determine if the loss of cell adhesion observed with HT1080-BMP-1 cells was triggered by a modification of cell adhesion receptors or a modification of the underlying ECM, we compared the adhesion of control HT1080 cells (chemically detached with EDTA) or HT1080-BMP-1 cells (either chemically or spontaneously detached) on the ECMs previously deposited by these cells. Although both cell types could adhere normally on the ECM deposited by control cells, their adhesion to the ECM of HT1080-BMP-1 cells was severely impaired (Fig. 1G). When observed under a microscope (fig. S2), few cells plated on the ECM deposited by HT1080-BMP-1 cells had adhered, and those remaining were round in shape and not spread; in contrast, cells could spread and firmly adhere to the ECM deposited by control cells. To determine whether cell adhesion on HT1080-BMP-1 ECM was completely impaired or just slightly delayed, HT1080 cells were allowed to adhere for up to $3.5 \mathrm{~h}$ on the conditioned ECMs, but no progress regarding cell spreading was observed with the ECM from BMP-1-expressing cells (Fig. 1H). These results led to the conclusion that the most important changes induced by the activity of BMP-1 occurred in the ECM, whereas the cell surface was not substantially altered.

BMP-1 cleaves thrombospondin-1 
Our next aim was to identify the ECM substrate(s) processed by BMP-1. Based on our knowledge of the repertoire of proteins secreted by HT1080 cells characterized in a previous study (31), we screened the most prominent ECM components produced by these cells using western blotting and identified thrombospondin-1 (TSP-1) as a promising candidate substrate. A fragment of TSP-1 migrating at around $120 \mathrm{kDa}$ accumulated in the conditioned medium of HT1080-BMP-1 cells (Fig. 2, A and B). This fragment was not detected in the medium of nontransfected cells (Fig. 2A) or when the HT1080-BMP-1 cells were treated with the BMP-1 inhibitor hxt (Fig. 2B). In vitro, the same fragment was released when TSP-1 (purified from human platelets) was incubated with recombinant BMP-1 (Fig. 2A). The fragment, called fragment 1, was also found to be present in the medium of 293-EBNA cells transfected with a BMP-1-encoding vector, whereas it was barely detectable in cells transfected with an empty vector (Fig. 2C). The latter result suggested that this specific TSP-1 cleavage event was common to the two cell lines that shared similar adhesion phenotypes. Finally, using antibodies with well-defined epitopes located in the TSP-1 type 2 and 3 repeats (A4.1 and A6.1 respectively (Fig. 2D); (42)), we could assign fragment 1 to the C-terminal part of TSP-1 (fig. S3, A and B).

In order to get more insight into the biochemical features of the proteolytic processing involved, we performed in vitro cleavage assays with varying proteinase concentrations and incubation times. The resulting products were analyzed by SDS-PAGE in reducing and non-reducing conditions (Fig. 2E). As expected, the cleavage products increased when the protease:substrate ratio or the incubation time was increased. However, the cleavage pattern was very dependent on the presence of reducing agents. Whereas two main cleavage products were observed at around 120 and $50 \mathrm{kDa}$ in reducing conditions (fragment 1 and fragment 2, respectively), four products - two above $200 \mathrm{kDa}$, one around $150 \mathrm{kDa}$, and one around $120 \mathrm{kDa}$ - were detected in non-reducing conditions. This apparent discrepancy can be explained by the trimeric nature of TSP-1, wherein molecules are held together by inter-chain disulfide bonds involving two cysteines in their Nterminal half (Fig. 2D); this resulted in intermediate species when only one or two chain(s) were cleaved, as observed in non-reducing conditions. We then analyzed the upper fragment (fragment 1) observed in reducing conditions by Nterminal Edman sequencing and could unambiguously localize the BMP-1 cleavage site between $\operatorname{Ser}^{375}$ and Asp ${ }^{376}(\mathrm{~N}-$ terminal sequence: DSADX), in precise agreement with the known specificity of BMP-1 (25). Moreover, cleavage site 
identification using a mass spectrometry-based approach involving isotopic labeling of neo-peptides (ATOMS; $(31,43)$ ) confirmed that the peptide starting with $\mathrm{Asp}^{376}$ and ending with $\mathrm{Arg}^{402}$ was much more abundant in the presence of BMP1 than in its absence (proteinase:control ratio $=47$ based on 5 identifications). Furthermore, two unusual posttranslational modifications on $\operatorname{Trp}^{385}$ (C-mannosylation) and $\operatorname{Ser}^{394}$ (disaccharide Glc-Fuc-O) were unambiguously detected on this peptide (fig. S4), confirming the findings of a previous study (44). From the identification of the cleavage site in the short linker between the trimerization domain (Von Willebrand factor C or VWFC) and TSP type 1 repeats (TSRs; Fig. 2D), we can infer that the $\mathrm{N}$-terminal product (fragment 2) is a trimer in non-reducing conditions (migrating around $150 \mathrm{kDa}$ ) and a monomer in reducing conditions (migrating around $50 \mathrm{kDa}$; Fig. 2, E-F and fig. S3) whereas fragment 1 is observed as a monomer in both conditions (migrating around $120 \mathrm{kDa}$ ).

\section{BMP-1-mediated cleavage releases the C-terminal fragment of TSP-1 from the ECM}

Our observations indicated that TSP-1 was cleaved in the conditioned medium of 293-EBNA and HT1080 cells if the cells expressed BMP-1, but the loss of cell adhesion also involved major modifications of the extracellular matrix (Fig. 1G). Using fluorescence microscopy with the MAB3074 antibody directed against the TSP-1 domains located downstream of the BMP-1 cleavage site, we observed a strong decrease of TSP-1 staining in the cell layer of HT1080BMP-1 cells before detachment compared to HT1080 and HT1080-E94A cells (Fig. 3A). In contrast and despite the fact that fibronectin is a known ligand of TSP-1, fibronectin fibrils did not seem to be modified by the presence of active BMP-1 (Fig. 3A). ECM extracts of the different cell types analyzed by western blotting also confirmed that full-length TSP-1 was present in the ECM deposited by control cells but almost completely absent from the ECM of BMP-1expressing cells (Fig. 3B). Finally, whereas TSP-1 fragment 1 was never detected in the ECM samples even using long exposure times, at least a fraction of fragment 2 remained, entrapped in the ECM compartment (Fig. 3C). These results indicated that BMP-1 cleaved the matrix-embedded TSP-1 and thereby triggered the release of the C-terminal part of the molecule from the ECM.

\section{Cleavage abolishes the ability of TSP-1 to promote cell adhesion}


Both the N- and C-terminal fragments of TSP-1 have the potential to play a role in cell adhesion. The N-terminal portion can interact with several cellular receptors, including integrins, heparan-sulfate proteoglycans, and calreticulin, and the most C-terminal domains found in fragment 1 can interact with integrins, CD36 and CD47 (also known as integrinassociated protein, IAP) $(45,46)$. Using siRNAs directed against human TSP-1, we first demonstrated that TSP-1 was critical for the adhesion of HT1080 cells. When TSP-1 was knocked down (by around $60 \%$ as determined by western blotting, fig. S5), the cells changed their morphology, became rounded and seemed to be more loosely attached to the plates (Fig. 4A). This was associated with a downward trend in cell area already visible $48 \mathrm{~h}$ after transfection (Fig. 4B) and a significant increase in the number of detached cells $72 \mathrm{~h}$ after transfection (Fig. 4C), similarly to previous observations made in HT1080-BMP-1 cells (Fig. 1, E and F).

In a second series of experiments, we analyzed whether cleaved TSP-1 was still capable of promoting HT1080 adhesion. Purified TSP-1 was first subjected to BMP-1 proteolytic activity for $4 \mathrm{~h}$, then incubated overnight in a 96-well plate, and adhesion of HT1080 cells to the cleaved and intact proteins was measured. We observed that processing by BMP-1 completely abolished the ability of TSP-1 to promote adhesion (Fig. 4D, condition 4). The loss of TSP-1 adhesive properties was clearly due to proteolysis, because incubation with the inactive mutant form of BMP-1 did not lead to the same effect (Fig. 4D, condition 3). Control experiments were also performed to exclude (i) protein unfolding after prolonged incubation at $37^{\circ} \mathrm{C}$ (the intact protein incubated in the same conditions was even slightly more active than the protein incubated at $4^{\circ} \mathrm{C}$, conditions 1 and 2) or (ii) differential coating efficiency of 96-well plates by intact and cleaved TSP-1 (fig. S6, A and B).

Finally, the contribution of soluble fragments 1 and 2 to the loss of cell adhesion was assessed through the adhesion of parental HT1080 cells to wells coated with TSP-1 in competition with intact, soluble TSP-1, purified fragment 1 or semipurified fragment 2 (fig. S7). We observed an increase in the adhesion of HT1080 cells (Fig. 4E) with increasing concentrations of intact, soluble TSP-1, possibly explained by the previously described ability of TSP-1 to recruit other TSP molecules through intermolecular contacts $(47,48)$. In contrast, equimolar amounts of either fragment 1 or fragment 
2 did not display significant effects on cell adhesion to TSP-1-coated wells (Fig. 4F). Individual fragments released into cell supernatants from matrix-embedded or soluble TSP-1 are therefore not expected to contribute substantially to the adhesion phenotype of HT1080 cells.

\section{Cleavage enhances the ability of TSP-1 to release active TGF- $\beta$}

In addition to mediating ECM-cell interactions, another major function of TSP-1 is to release the active form of TGF- $\beta$ which, after secretion, remains non-covalently bound to its latency-associated peptide (LAP) prodomain and, in this tightly-interacting complex, is kept in the latent form. When TSP-1 was added to HT1080 cells, the canonical TGF- $\beta$ pathway was indeed found to be activated, as evidenced by the detection of the phosphorylated form of the downstream effector SMAD2 60 min after TSP-1 addition (Fig. 5A). We also analyzed the ability of cleaved TSP-1 (provided to the cells as a mixture of TSP-1 fragments plus BMP-1 without any further purification of the in vitro reaction) to trigger TGF- $\beta$ signaling and found that it even more efficiently induced SMAD2 phosphorylation compared to the intact protein (Fig. 5A). After quantitation and normalization to the amount of actin or total SMAD2, the enhancement ratio was calculated to be around 2.7 (Fig. 5B). The increased TGF- $\beta$ activation capacity of cleaved TSP- 1 was confirmed using a luciferase reporter assay (31). At the two concentrations of TSP-1 that were tested (14 and $41 \mathrm{nM})$, luciferase activity was more than 2-fold higher after incubation with active BMP-1 than with inactive BMP-1 or buffer alone (Fig. 5C). This suggested a higher TGF- $\beta$ activation capacity of cleaved TSP-1 compared to the full-length form.

The TSRs of TSP-1, which are located in fragment 1 just after the BMP-1 cleavage site, mediate the capacity of TSP- 1 to activate TGF- $\beta$ (49). We tested whether purified fragment 1 was also capable of promoting TGF- $\beta$ activation in the same conditions in which intact TSP-1 did. Intriguingly, we found that it did not elicit any increase in SMAD2 phosphorylation (Fig. 5D). To explain the apparent discrepancy, we analyzed the amounts of residual TGF- $\beta$ and LAP that were bound to intact TSP-1 and fragment 1 . Using purified mature TGF- $\beta$ as a control, we estimated that our TSP-1 preparations reproducibly carried about 1 molecule of dimeric small latent TGF- $\beta$ complex for every 100 molecules of trimeric TSP-1 (Fig. 5E) despite the high-pH stripping procedure used in the purification protocol. In contrast, purified fragment 1 was 
found to be totally devoid of TGF- $\beta$ and LAP, suggesting that cleavage by BMP-1 promoted the dissociation of latent TGF- $\beta$ (LTGF- $\beta$ ) from TSP-1. However, this decreased stability did not preclude the activation of LTGF- $\beta$ by fragment 1, because SMAD signaling significantly increased when an exogenous source of LTGF- $\beta$ was added to HT1080 cells after a short incubation at $37^{\circ} \mathrm{C}$ with fragment 1 (Fig. 5F). This effect was consistent between two different batches of fragment 1 with an activation efficiency similar to that achieved by treatment of LTGF- $\beta$ with $10 \mathrm{mM} \mathrm{HCl}$ and superior to that of intact TSP-1 (Fig. 5G). Note that TSP-1 final concentration in cell medium is too low $(1.2 \mathrm{nM})$ in the conditions of this assay to trigger detectable SMAD2 phosphorylation when provided alone to the cells.

Together, these experiments suggest that (i) purified platelet TSP-1 promoted SMAD signaling through the release of its own TGF- $\beta$ load rather than through the activation of cell-secreted LTGF- $\beta$ (Fig. 5A, D and E); (ii) cleavage of TSP-1 by BMP-1 and the subsequent loss of TSR trimeric organization enhanced the activation and release of the TGF- $\beta$ bound to TSP-1 (Fig. 5E, F and G); (iii) fragment 1 did not act as a reservoir of LTGF- $\beta$ but was very efficient to activate the growth factor from exogenous sources of the latent complex (Fig. 5E, F and G).

\section{TSP-1 is physiologically cleaved in human primary keratocytes and induces myofibroblast differentiation}

To get further insight into the effect of the type of ECM proteins synthesized by cells on the BMP-1-dependent adhesion phenotype, we assessed the effect of increasing or decreasing the activity of BMP-1 in the culture medium of human primary keratocytes (corneal stromal cells), which secrete a collagen-rich ECM and have been demonstrated to be a suitable model studying BMP-1 activity $(31,35)$. We found no change in the adhesion profile of keratocytes in BMP-1supplemented culture medium, a condition in which HT1080 cell adhesion was greatly reduced (Fig. 6A). However, when we assayed TSP-1 in the conditioned medium of the keratocytes, we detected three forms, corresponding to full-length TSP-1 and to cleaved products similar in size to the fragments 1 and 2 described above (Fig. 6B). These fragments were diminished in the presence of BMP-1 inhibitors and increased upon the addition of exogenous BMP-1 (Fig. 6, B and C), demonstrating the direct involvement of the proteinase in generating the fragments. When the ECM of keratocytes was analyzed, full-length TSP-1 was still present in large amounts (Fig. 6B) despite clear evidence of BMP-1-dependent 
cleavage of the matrix-embedded TSP-1. Indeed, like in HT1080 cells, fragment 2 was detected in the keratocyte ECM but fragment 1 was missing. These results indicated that the endogenous amounts of BMP-1 produced by human keratocytes (Fig. 6D) were sufficient to cleave soluble and insoluble TSP-1 but that these cells do not rely on the same mechanisms as HT1080 cells to adhere to their extracellular matrix.

We also analyzed the ability of cleaved TSP-1 to trigger TGF- $\beta$ signaling in primary keratocytes. Similarly to what was observed for HT1080 cells, we observed an increase in the amount of SMAD phosphorylation in the presence of cleaved TSP-1 compared to full-length TSP-1 (Fig. 7, A and B). In addition, cleaved TSP-1 was significantly more efficient than intact TSP-1 in inducing the production of TGF- $\beta$ target genes such as $\alpha$-smooth muscle actin ( $\alpha$-SMA; Fig. 7, C and D). This further shows that the cleavage of TSP-1 by BMP-1 promoted the differentiation of keratocytes into myofibroblasts.

\section{TSP-1 is cleaved in human corneal scars}

Because both BMP-1 and TSP-1 have previously been proposed to play a role in the development of corneal scarring (10, 50), we analyzed 4 human corneas from patients presenting with permanent corneal scars and collected at the time of corneal transplantation. Scars were caused by perforating traumas or corneal ulcers that occurred between 6 and 26 months before surgery. In the lysates of all 4 corneas, a TSP-1 product migrating at the same size as the fragment 1 identified in keratocyte supernatant was detected (Fig. 8A). This result suggested that BMP-1-dependent processing of TSP-1 also occurred in vivo and could contribute to the development of corneal scars.

\section{BMP-1-dependent proteolysis of TSP-1 induces myofibroblast differentiation in an ex vivo model of mouse corneal}

\section{wound healing}

In order to get further insights into the potential roles of TSP-1 fragments in corneal wound healing, we adapted a previously described ex vivo model of corneal wound healing (51). Because it was not possible to gather enough human corneas to compare all possible conditions, we used murine corneas and created calibrated wounds in the center of the corneas with 1 mm-diameter biopsy punches (Fig. 8, B and C). The wounded corneas were then placed in culture medium 
for 1 week and treated twice with intact TSP-1, cleaved TSP-1, cleaved TSP-1 in combination with the TGF- $\beta$ type I receptor inhibitor SB431542 (52) or appropriate controls (vehicle, BMP-1, and TGF- $\beta$ ), at days 2 and 4. We measured wound contraction once a day, calculated as the percentage of initial wound area, and observed that the wound area was significantly decreased in corneas treated with cleaved TSP-1 at days 6 and 7 compared to corneas treated with vehicle (Fig. 8D). Also, the combination of cleaved TSP-1 and SB431542 followed a curve that nearly superimposed on the vehicle curve and led to a significant reduction of wound contraction compared to treatment with cleaved TSP-1 alone.

After 7 days in culture, corneas were stained for $\alpha$-SMA. As observed in the first days of corneal wound healing in vivo (53), keratocytes located close to the wound died by apoptosis whereas stromal cells from the wound margins proliferated and activated to acquire a myofibroblast phenotype (Fig. 8E). This showed that our model was relevant to analyze keratocyte activation, and we proceeded to evaluate the number of cells that differentiated into myofibroblasts by immunofluorescence. This analysis indicated a strong increase in the percentage of cells at the wound margins that were myofibroblasts when corneas were treated with cleaved TSP-1 or TGF- $\beta$ compared to treatment with vehicle, BMP-1, or intact TSP-1 (Fig. 8, E and F). In addition, the effect of cleaved TSP-1 was confirmed to be mediated by TGF- $\beta$ because SB431542 completely reversed the induction of $\alpha$-SMA production elicited by cleaved TSP-1 alone. This established that cleaved TSP-1 was a potent inducer of myofibroblast differentiation through the release of bound TGF- $\beta$, both in 2D cultures and in the 3D physiological environment of the cornea, and, based on the observation of cleaved TSP-1 in human corneal scars, that it was highly likely to play a role in wound healing in vivo.

\section{DISCUSSION}

Cell growth, survival, and differentiation result from the integration of numerous mechanical and molecular cues present in the external environment of cells. One prominent source of these signals is the ECM that surrounds cells and provides a great diversity of components with various abilities to promote cell adhesion through specific interactions with cellular 
receptors. Here, we show that, by directly modifying the ECM, BMP-1 strongly alters the ability of two cell types to adhere.

Several metalloproteinases have previously been shown to induce a similar disruption of cell-matrix contacts, both through proteolytic and non-proteolytic activities $(54,55)$. In the present case, the drastic alterations of cell properties induced by BMP-1 in HT1080 and 293-EBNA cells clearly depended on its catalytic activity, and we linked the loss of adhesion to the cleavage of TSP-1. Several sites in TSP-1 that interact with cellular receptors have been identified (45, 46, 56), including domains that mediate interactions with calreticulin (TSPN domain; Fig. 2D), $\beta 1$ integrins (TSPN domain, type 1-3 repeats), $\beta 3$ integrins (type 3 repeats), heparan sulfate proteoglycans (TSPN domain, type 1 repeats), CD36 (type 1 repeats), and CD47 (C-terminal domain). As a result, the adhesive properties of TSP-1 will depend on several parameters such as (i) the cell type (which determines the specific repertoire of cell receptors); (ii) the local TSP-1 concentration and availability (which is potentially limited by the occupancy of receptor binding sites by other TSP-1 partners); and (iii) whether TSP-1 is soluble or matrix-bound. In addition, previous reports have shown that proteolysis of TSP-1 can also affect cell adhesion (57-59). In one of these studies, Ash et al. demonstrated that HT1080 cells can attach and spread on surfaces coated with TSP-1 (58) through a multi-site cooperative attachment process involving both the interaction of the N-terminal TSPN domain with heparan-sulfate proteoglycans and the interaction of TSRs with CD36 (Fig. 2D). They also observed that HT1080 cells can attach but do not spread on a $140 \mathrm{kDa}$ C-terminal fragment of TSP1, generated by thrombin cleavage (Fig. 2D) and lacking the heparin-binding TSPN domain (58). In contrast, they can neither attach nor spread on the TSPN domain alone (58). Finally, the same authors ruled out the involvement of integrins such as the $\alpha_{v} \beta_{3}$ integrin, an important TSP-1 cell receptor present on HT1080 cells and mediating adhesion through interactions with the RGD sequence in type 3 repeats, because the RGDS peptide has no effect on cell adhesion.

BMP-1 cleaves TSP-1 between the procollagen-like/VWFC domain and the TSRs (Fig. 2D) at a site (Ser ${ }^{375} \downarrow \mathrm{Asp}^{376}$ ) that is highly conserved in TSP-1 from a wide range of species but not present in human TSP-2 (fig. S8). The cleavage site location is different from the one targeted by thrombin and other serine proteases reported to make single cuts in TSP-1 
$\left[\mathrm{Val}^{214} \downarrow \operatorname{Arg}^{215}\right.$ for HtrA1 (60), $\operatorname{Arg}^{255} \downarrow \operatorname{Thr}^{256}$ for cathepsin G (61) and $\operatorname{Tyr}^{258} \downarrow$ Ile $^{259}$ for kallikrein 7 (62)] and seems to have an even stronger effect on the adhesion of HT1080 cells on TSP-1 than does the thrombin cleavage site. Even the Cterminal fragment 1 containing the CD36 interaction site, when provided in equimolar concentration with fragment 2 , lost its ability to promote cell attachment (Fig. 4D). Because processing occurs just N-terminal to the known CD36 interaction site located within the second type 1 repeat (56), it is most likely that the cleavage by BMP-1 induces a major conformational rearrangement of this region, at the level of each polypeptide chain and/or of the quaternary structure (through the loss of the trimeric organization), thereby leading to disruption of the CD36 interaction site. This effect on the CD36 binding site is likely to impact other cell types, especially endothelial cells, for which CD36 is a major TSP-1 receptor (63), with possible consequences for the regulation of angiogenesis (Fig. 9). This also suggests new hypotheses linking BMP-1 expression with neovascularization $(17,64)$ and could explain some of the tumor-promoting activities described for BMP-1 (19-21, 65, 66).

In addition, we observed that the BMP-1-dependent cleavage of TSP-1 triggered the release of the TSR-bearing fragment (fragment 1) from the matrix, whereas the N-terminus was still present in the ECM. A similar mechanism of transfer from the matrix to the soluble phase has been previously observed upon cleavage of TSP-1 by ADAMTS-1 (67) at an upstream site located just before the VWFC domain (Glu ${ }^{311} \downarrow \mathrm{Leu}^{312}$; Fig. 2D), which also generates monomeric C-terminal fragments. These observations are in agreement with the previous demonstration that TSP-1 accumulation in the ECM is mediated by its L-type lectin C-terminal domain, through intermolecular interactions with itself or TSP-5 (also known as cartilage oligomeric protein, COMP), a process that requires the trimeric form of this domain and is not supported by monomers $(47,48)$. Finally, we tested whether the competition between insoluble TSP-1 and soluble fragments could be another possible de-adhesive mechanism and found that fragments 1 and 2 had no significant inhibitory or enhancing effect on HT1080 adhesion to TSP-1-coated surfaces, despite the presence of the hep I sequence, which is known to promote focal adhesion disassembly (68), in fragment 2. In summary, the observed loss of adhesion in cultures of HT1080 and 293-EBNA cells probably arises from the combined effects of (i) structural rearrangements disrupting 
receptor binding sites in fragment 1 , (ii) the interruption of cooperativity mechanisms between both sides of the cleavage site, and (iii) the decreased amount of the C-terminal region of the protein in the ECM.

As illustrated here in the case of keratocytes, the processing of TSP-1 by BMP-1 does not always lead to the disruption of cell-matrix interactions. Actually, despite relatively high endogenous amounts of processed TSP-1, keratocyte adhesion does not seem affected by the inhibition of endogenous BMP-1 nor by the addition of exogenous BMP-1. Although receptors possibly involved in the adhesion of keratocytes to TSP-1 have not been described, they are likely to differ from those on HT1080 cells and could be differently affected by TSP-1 cleavage. Also, other molecules in keratocyte ECM could compensate for the loss of intact TSP-1. In this regard, an important difference between primary keratocytes and the other cell lines studied is that HT1080 and 293-EBNA cells do not produce any fibrillar collagens, whereas these collagens are known to represent the main anchoring molecules for keratocytes in the corneal environment. We can therefore conclude that, in the case of keratocytes, the pro-adhesive signals that are also mediated by BMP-1 (for example through the promotion of collagen fibrillogenesis) largely outweigh the anti-adhesive signals potentially elicited by TSP-1 cleavage (Fig. 9). An additional level of complexity is brought by the fact that TSP-1 is also known to be required for proper collagen fibrillogenesis. The mechanism has been partially elucidated and involves TSP-1 interaction with fibrillar procollagens and pro-lysyl oxidase (pro-LOX), leading to the inhibition of LOX-mediated cross-linking in collagen fibers (69). Because procollagens and pro-LOX also undergo proteolytic maturation by BMP-1, we can hypothesize that TSP-1 inhibits LOX processing through competition for the BMP-1 active site. Inversely, we can expect that TSP-1 cleavage will be inhibited in the presence of pro-LOX and procollagens. However, the spatio-temporal regulation of the various proteolytic events to obtain correctly assembled and cross-linked fibers is not known and needs further investigation.

In parallel to the cell-dependent effect of TSP-1 cleavage on cell adhesion, we demonstrate that TSP-1 proteolysis by BMP-1 strongly enhances TGF- $\beta$ activity. The mechanism by which TSP- 1 converts LTGF- $\beta$ into active TGF- $\beta$ has been well studied (49). This involves the disruption of specific non-covalent interactions between the mature TGF- $\beta$ growth factor and its LAP propeptide through competing interactions between the type 1 repeats in TSP-1 and both components 
of the LTGF- $\beta$ complex. In particular, the KRFK sequence located at the beginning of the second TSR can efficiently replace the RKPK sequence in TGF- $\beta$ to interact with the LSKL sequence in LAP, thereby leading to the exposure of TGF- $\beta$, which otherwise remains buried within the LTGF- $\beta$ complex $(49,70)$. This mechanism implies a tight interaction between TSP-1 and LTGF- $\beta$ well illustrated by the fact that the TSP-1 purified from human platelets always contains some contaminating LTGF- $\beta$. In our cell-based assays, this bound LTGF- $\beta$ seemed to account for most of the observed induction of SMAD signaling. In contrast, purified fragment 1 displayed an enhanced ability to activate LTGF- $\beta$ but was completely deprived of bound TGF- $\beta$. Thus, we hypothesize that TSP- 1 cleavage potentiates the activity of TGF- $\beta$ by speeding up its release from all remaining interactions with TSP-1, thereby increasing its mobility and facilitating its access to signaling receptors. This represents another mechanism by which BMP- 1 enhances TGF- $\beta$ signaling, to be added to the previously reported cleavages of LTBP-1, TGF- $\beta$ receptor III (also known as betaglycan), and CD109 (31, 32). These mechanisms can all synergize to increase the pool and bio-availability of active TGF- $\beta$, and we can expect major consequences for the control of tumor progression, immunity, and wound healing (Fig. 9).

The potentiation of TGF- $\beta$ signaling by cleaved TSP-1 is common to HT1080 cells and keratocytes, and our results indicate that it can play a role in the differentiation of the latter into myofibroblasts. This is of great importance in the context of corneal wound healing, where it was previously reported that TSP-1 production precedes $\alpha$-SMA induction and could regulate myofibroblast recruitment into the wound (50). After wound closure, stromal remodeling remains active until myofibroblasts disappear from the wound, a process which can take several years and lead to scarring. The control of myofibroblast differentiation is therefore a major issue to prevent the formation of irreversible scars. Here, we demonstrate that the capacity of TSP-1 to induce the differentiation of keratocytes into myofibroblasts is significantly enhanced after cleavage by BMP-1, both in 2D cultures and in the 3D environment of the cornea. This adds another important role for this proteinase in corneal wounds and scars where its abundance is known to be strongly increased and it is found co-localized with $\alpha$-SMA (10). Our present results show that a BMP-1-dependent processed form of TSP-1 is also found in human corneal scars, therefore providing a mechanistic hypothesis to explain how BMP-1 can drive pathological healing through the regulated proteolysis of TSP-1. Notably, despite the numerous proteases known to 
process TSP-1, only the BMP-1-mediated cleavage product was detected by immunoblotting in human samples. However, it remains to be established whether this catabolic fragment is specific to corneal wounds or scars given that it is also produced by normal keratocytes in culture and could contribute to maintain tissue homeostasis.

The importance of regulated proteolysis, in contrast to degradation, to finely tune the properties and activities of ECM proteins has been demonstrated in several pathophysiological remodeling processes, including development, wound healing, fibrosis, and cancer. The unique location of the BMP-1 cleavage site in TSP-1, just before the type 1 repeats that mediate a large number of its activities, identifies another important regulatory mechanism to control cell adhesion and TGF- $\beta$ signaling in a concerted manner. This also confirms that proteolysis is an important aspect of TSP-1 regulation and establishes BMP-1 as a key molecular hub to coordinate the crosstalk between ECM-derived cues and growth factor signaling.

\section{MATERIALS AND METHODS}

\section{Cell culture}

HT1080 cells (ATCC CCL-121) were grown in Dulbecco's modified Eagle's medium (DMEM) with $10 \%$ fetal calf serum (FCS) and $50 \mu \mathrm{g} / \mathrm{ml}$ gentamycin. HT1080 cells, stably transfected with a piRESneo 2 vector encoding human BMP-1 fused with a 6His tag at the C-terminus or the same construct with the E94A mutation, were obtained and grown in DMEM with $10 \% \mathrm{FCS}$ and $250 \mu \mathrm{g} / \mathrm{ml} \mathrm{G} 418$ sulfate, as described previously (31). 293-EBNA cells overexpressing human native BMP-1 or human BMP-1 fused to a C-terminal Flag-tag were also available from previous studies $(37,71)$. A control 293-EBNA cell line transfected with the empty pCEP4 vector was produced using the same protocol. Primary keratocytes from human corneas were isolated as previously described (31), in accordance with ethical regulations, and grown in DMEM/Ham's F12 (1:1), $10 \%$ iron-supplemented calf serum, $5 \mathrm{ng} / \mathrm{mL}$ bFGF and $1 \%$ antibiotic/antimycotic solution. All cells were verified for the absence of mycoplasma with the MycoAlert detection kit (Ozyme). 
For conditioned medium analysis by western blotting, the cells were extensively washed with PBS (phosphate buffer saline) and maintained between 8 and $48 \mathrm{~h}$ in serum-free medium. The medium was then collected, centrifuged at $200 \mathrm{~g}$ for $5 \mathrm{~min}$, supplemented with protease inhibitors (Complete, Roche) and stored at $-80^{\circ} \mathrm{C}$. The extracellular matrix from the same cultures was also collected after solubilization in $0.325 \mathrm{M}$ Tris- $\mathrm{HCl} \mathrm{pH} 6.9,25 \%$ glycerol and $10 \%$ SDS. Prior to this step, cells were removed by adding $20 \mathrm{mM} \mathrm{NH}{ }_{4} \mathrm{OH}$ for $5 \mathrm{~min}$ and the matrix was washed several times with water. Equal amounts of total proteins (medium, determined by Bradford assay) or equal volumes (ECM) were loaded onto the gels for Western blot analyses.

\section{Proteins and inhibitors}

Recombinant human BMP-1 and Xenopus sizzled were produced and purified as previously described (40, 72).

Recombinant human TGF- $\beta 1$ (Ala ${ }^{279}-$ Ser $^{390}$ ) was from Peprotech (Ref. 100-21) and human latent TGF- $\beta$ (Leu ${ }^{30}-$ Ser $^{390}$ ) was from R\&D Systems (ref. 299-LT-025/CF). Thrombospondin-1 was purified from human platelets, provided by the Etablissement Français du Sang (Lyon) in agreement with French regulations, according to the protocol developed by Lawler and co-workers (73) with minor modifications. In brief, after 3 washes in Baezinger A buffer $(0.102 \mathrm{M} \mathrm{NaCl}, 3.9$ $\mathrm{mM} \mathrm{K}_{2} \mathrm{HPO}_{4}, 3.9 \mathrm{mM} \mathrm{Na}_{2} \mathrm{HPO}_{4}, 22 \mathrm{mM} \mathrm{NaH}_{2} \mathrm{PO}_{4}, 5.5 \mathrm{mM}$ glucose $\mathrm{pH}$ 6.3), the platelet pellet was resuspended in Baezinger B buffer (15 mM Tris, $0.14 \mathrm{M} \mathrm{NaCl}, 5 \mathrm{mM}$ glucose $\mathrm{pH}$ 7.6) with $2 \mathrm{mM} \mathrm{CaCl}_{2}$ (50 $\mathrm{mL}$ of buffer for approximately $3 \mathrm{~mL}$ of pellet). Fifty $\mathrm{mL}$ of resuspended platelets were then gently mixed for 2 min at room temperature with $50 \mathrm{u}$ thrombin (GE Healthcare) and kept on ice for 5-10 min until complete aggregation. After centrifugation at 1,400 $\mathrm{g}$ for $5 \mathrm{~min}, 1 \mathrm{mM}$ Pefabloc was added to block thrombin activity. The supernatant was further centrifuged at $35,000 \mathrm{~g}$ for $20 \mathrm{~min}$ at $4{ }^{\circ} \mathrm{C}$, stored at $4^{\circ} \mathrm{C}$ for one night and centrifuged again at $1,400 \mathrm{~g}$ for $20 \mathrm{~min}$. This was followed by heparin Sepharose chromatography (6 Fast Flow, GE Healthcare) using a $0.15 \mathrm{M} \mathrm{NaCl}$ to $2 \mathrm{M} \mathrm{NaCl}$ gradient in $15 \mathrm{mM}$ Tris pH 7.6, $2 \mathrm{mM} \mathrm{CaCl}_{2}$. TSP-1-containing fractions were then pooled, concentrated in an Amicon Ultra device (cut-off $100 \mathrm{kDa}$, Millipore) and injected on a Superdex S200 16/600 column equilibrated in $20 \mathrm{mM}$ Tris pH 11, $0.15 \mathrm{M} \mathrm{NaCl}, 2$ $\mathrm{mM} \mathrm{CaCl}_{2}$. The $\mathrm{pH}$ of the major peak fractions was then rapidly decreased to 7.5-8.0 and the protein was concentrated, 
dialyzed against $20 \mathrm{mM}$ HEPES pH 7.4, $0.5 \mathrm{M} \mathrm{NaCl}, 2.5 \mathrm{mM} \mathrm{CaCl}_{2}$ and flash-frozen in liquid nitrogen before storage at $-80^{\circ} \mathrm{C}$ in LoBind microtubes (Eppendorf).

TSP-1 fragments 1 and 2 were generated by the cleavage of 400-700 $\mu$ g of purified TSP-1 in the presence of an equimolar amount of recombinant BMP-1 in $50 \mathrm{mM}$ HEPES pH 7.4, $0.16 \mathrm{M} \mathrm{NaCl}, 5 \mathrm{mM} \mathrm{CaCl} 2,0.02 \%$ n-octyl- $\beta$-D-

glucopyranoside for $4 \mathrm{~h}$ at $37^{\circ} \mathrm{C}$. Immediately after the cleavage, the mixture was loaded on a HiTrap heparin HP column ( $1 \mathrm{~mL}, \mathrm{GE}$ Healthcare) and purified with a $\mathrm{NaCl}$ gradient (from 0.16 to $2 \mathrm{M}$ ). This yielded pure fragment 1 in the flowthrough and enriched fragment 2 in the eluate. Useful fractions were concentrated and injected on a Superdex S200 16/600 gel filtration column equilibrated in $20 \mathrm{mM}$ HEPES pH 7.4, $0.5 \mathrm{M} \mathrm{NaCl}, 2.5 \mathrm{mM} \mathrm{CaCl}_{2}$. After concentration, fragments were stored in the same conditions as full-length TSP-1. By SDS-PAGE, fragment 2 still contained full-length TSP-1 and BMP-1, around $20 \%$ each (fig. S7).

The BMP-1 hydroxamate inhibitor used in cell cultures was the N-substituted aryl sulfonamide hydroxamate 90 described in (74), also known as S33A, which was prepared and characterized as reported $(31,39)$. It was dissolved in DMSO before addition to the culture medium. The TGF- $\beta$ type I receptor inhibitor SB431542 was from Sigma-Aldrich.

\section{Quantification of cell numbers and detachment}

Cells were counted either manually (in a Thoma chamber) or with a Cellometer AutoT4 (Nexcelom). For the monitoring of 293-EBNA cell detachment over time, 7,000 cells/well were seeded in 96-well plates and grown in DMEM, $10 \%$ FCS, $300 \mu \mathrm{g} / \mathrm{mL}$ hygromycin. After 7 days, cells were washed and switched to serum-free medium. At each time point, cell supernatants were transferred to plates coated with poly-D-lysine. Both adherent and detached cells were fixed with $4 \%$ glutaraldehyde and stained with $0.1 \%$ crystal violet for quantification.

\section{Immunoblotting}


The percentages of acrylamide used for SDS-PAGE and immunoblotting were as follows : 6 or $8 \%$ for TSP-1, $10 \%$ for BMP-1 and P-SMAD2, $8 \%$ for SMAD2 and 3, 4-20 \% for LAP and TGF- $\beta$. After SDS-PAGE, proteins were transferred to PVDF membranes by liquid transfer $\left(2 \mathrm{~h}, 4^{\circ} \mathrm{C}, 250 \mathrm{~mA}\right)$ in $10 \mathrm{mM}$ CAPS (N-cyclohexyl-3-aminopropanesulfonic acid) pH 11 with $10 \%$ ethanol and blocked for $2 \mathrm{~h}$ in $10 \%$ (w/v) skim milk in PBS. Primary antibodies were diluted in $5 \%$ skim milk, $0.05 \%$ Tween-20 in PBS and applied on membranes overnight at $4^{\circ} \mathrm{C}$. After 3 washes in $0.05 \%$ Tween-20 in PBS, HRP-coupled secondary antibodies (Cell Signaling Technology or Dako, dilutions 1/5,000 or 1/10,000) were added for $1 \mathrm{~h}$ at room temperature and signal was detected using the enhanced chemiluminescence technique with the ECL Select (GE Healthcare) or Clarity Max (Biorad) kits and the FX Fusion CCD camera (Vilber Lourmat).

Unless otherwise stated, TSP-1 detection was with the mouse monoclonal antibody MAB3074 from R\&D Systems $(1 / 1,000)$. Other anti-TSP-1 antibodies included the mouse monoclonal antibodies A4.1 (1/200) and C9 (1/100) from Santa-Cruz Biotechnology, the mouse monoclonal antibody A6.1 (1/500) from eBioscience and the rabbit polyclonal antibody AP8522a from Abgent (1/500). The rat monoclonal anti-human BMP-1 (MAB1927; 1/1,000) antibody was from R\&D Systems, the rabbit polyclonal anti-human collagen VI antibody $(20611 ; 1 / 200)$ from Novotec, the mouse monoclonal anti-actin $(A 3854 ; 1 / 3,000)$ from Sigma-Aldrich and the rabbit polyclonal anti-SMAD2/3 $(3102 ; 1 / 1,000)$ and anti-Phospho-SMAD2 (Ser465/467; 3108; 1/1,000) antibodies were from Cell Signaling Technology..

\section{Microscopy}

Phase contrast images were taken with a Nikon TE300 microscope, a Nikon Ti-E microscope or a Zeiss Axioplan microscope equipped with a DIC module. For videomicroscopy experiments, 40,000 cells/well of each cell type were seeded in a 6-well plate and grown for $24 \mathrm{~h}$ in DMEM containing $10 \%$ FCS. Images were taken every $15 \mathrm{~min}$ for $17 \mathrm{~h}$.

For cell area measurements, 5,000 cells/well were seeded in 8-well $\mu$-slides (Ibidi) and grown for 3 days in complete growth medium. Then, cells were fixed with $4 \%$ paraformaldehyde and stained with phalloïdin-FITC and DAPI. Images were acquired using a Zeiss Axio Observer Z1 microscope equipped with a 20x NA 0.8 objective or a Zeiss LSM710 
microscope equipped with a $63 x$ NA 1.4 objective. To extract the mean cell area, the total surface covered by cells in each field was revealed by actin staining and measured using the FIJI software (75). This surface was then divided by the number of nuclei detected by DAPI staining in the field.

For extracellular TSP-1 and fibronectin immunostaining, cells were grown on coverslips for 3 days and fixed with $4 \%$ paraformaldehyde. No permeabilization was performed. Cells were incubated with MAB3074 anti-TSP-1 (1/50) or A0245 anti-fibronectin (Dako, 1/500) primary antibodies and immunostaining was revealed with goat anti-mouse or antirabbit cyanin 3 secondary antibodies (115-165-146 and 111-165-144 respectively from Jackson ImmunoResearch; 1/1,000). Nuclei were stained with DAPI. Fluorescence images were taken using a Zeiss Axio Observer Z1 microscope equipped with an Orca-R2 CCD camera (Hamamatsu Photonics). For fibronectin images, maximum intensity projections of stacks, generated using FIJI, are shown.

For the staining of $\alpha$-SMA in human keratocytes, 50,000 cells/well were seeded in 6-well plates in complete growth medium. After one day, cells were washed with PBS and treated for $72 \mathrm{~h}$ with TGF- $\beta$, intact TSP-1, cleaved TSP-1 or vehicle solutions in serum-free medium. Then, cells were fixed and permeabilized with cold methanol. Immuno-detection was carried out with anti- $\alpha$-SMA (Ab5694 from AbCam; 1/500) and anti-rabbit Alexa Fluor 594 (A-11037 from Thermo Scientific; 1/1,500) antibodies. Nuclei were stained with DAPI. Fluorescence images were taken using a Zeiss Axioplan 2 microscope and $\alpha$-SMA positive cells (with clear organized fibers) were counted using FIJI in 20 different fields/condition.

\section{Flow cytometry}

150,000 or 500,000 HT1080 cells were seeded in $100 \mathrm{~mm}$ culture dishes and grown for $48 \mathrm{~h}$ to obtain around 20 and 50 $\%$ confluency. Cells were then detached with accutase (Sigma-Aldrich), washed with PBS and with the binding buffer provided in the Annexin V-FITC Apoptosis detection kit (BioVision). 500,000 cells were resuspended in $500 \mu 1$ binding 
buffer, incubated for 5 min with $5 \mu 1$ of Annexin V-FITC and $5 \mu 1$ of propidium iodide in the dark and analyzed with a

FACS LSR II apparatus (Becton Dickinson) equipped with the FACSDiva software.

\section{RNA interference}

TSP-1 expression in HT1080 cells was decreased using validated siRNAs directed against human TSP-1 from Qiagen (Hs_THBS1_5 with target sequence 5'-TACGAATGTAGAGATCCCTAA and HS_THBS1_7 with target sequence 5'CGGCGTGAAGTGTACTAGCTA). A control siRNA against the decoy sequence 5'-AATTCTCCGAACGTGTCACGT was also used. 120,000 or 300,000 HT1080 cells/well were seeded in 12- or 6-well plates with DMEM containing $10 \%$ FCS. Thirty min after seeding, transfection mixes containing siRNA, DMEM and HiPerFect Transfection Reagent (Qiagen), prepared as recommended by the manufacturer, were added to the cells ( $25 \mathrm{nM}$ final siRNA concentration). Pictures were taken every $24 \mathrm{~h}$ for 3 days and the medium was collected at day 3 (after $48 \mathrm{~h}$ of serum starvation), either for western blot analysis or for the quantification of detached cells. Remaining adherent cells were also counted after trypsination and resuspension in PBS. For cell area measurements, 31,500 cells/well were seeded in 8-well $\mu$-slides (Ibidi, $1 \mathrm{~cm}^{2}$ ) in complete growth medium and transfected in the same conditions as above. After $24 \mathrm{~h}$, medium was changed to serum-free medium and cells were maintained in this medium for another day before fixation with $4 \%$ paraformaldehyde. Staining with phalloïdin-FITC and DAPI, imaging and cell area measurement were performed as described in the "Microscopy" section.

\section{In vitro cleavage assays and $N$-terminal sequencing}

All cleavage assays were performed at $37^{\circ} \mathrm{C}$ in $40-200 \mu$ l of $50 \mathrm{mM}$ HEPES pH 7.4, $0.15 \mathrm{M} \mathrm{NaCl}, 5 \mathrm{mM} \mathrm{CaCl}_{2}, 0.02 \%$ n-octyl- $\beta$-D-glucopyranoside (buffer A). Incubation time and protease:substrate ratios were varied as indicated. Cleavage monitoring was performed by SDS-PAGE and detection was with Coomassie Blue. For Edman N-terminal sequencing, $10 \mu \mathrm{g}$ of TSP-1 were incubated with and without $4 \mu \mathrm{g}$ BMP-1 in $200 \mu \mathrm{l}$ buffer A for $4 \mathrm{~h}$. The two samples were then processed for Edman sequencing on PVDF membranes and analyzed with an Applied Biosystems 473 protein sequencer. 
For ATOMS experiments, half the amounts of BMP-1 and TSP-1 (keeping concentrations constant) were used. Samples were processed as described in (31) and peptides were analyzed with a Q-Exactive HF tandem mass spectrometer (Thermo Scientific) coupled to an Ultimate 3000 nanoLC system (Dionex) (76). Briefly, peptides were first desalted on line on a reverse phase Acclaim PepMap100 C18 precolumn ( $5 \mu \mathrm{m}, 100 \AA, 300 \mu \mathrm{m}$ id x $5 \mathrm{~mm})$ for $5 \mathrm{~min}$ at $2 \% \mathrm{CH}_{3} \mathrm{CN}$ at a flow rate of $10 \mu \mathrm{l} / \mathrm{min}$, and then resolved at a flow rate of $0.300 \mu \mathrm{l} / \mathrm{min}$ with a $180 \mathrm{~min}$ gradient of $\mathrm{CH}_{3} \mathrm{CN}_{,} 0.1 \%$ formic acid applied onto the reverse phase Acclaim PepMap100 C18 column ( $3 \mu \mathrm{m}, 100 \AA, 75 \mu \mathrm{m}$ id x $500 \mathrm{~mm})$ from 4 to $40 \% \mathrm{CH}_{3} \mathrm{CN}$. The Q-Exactive $\mathrm{HF}$ instrument was operated according to a Top20 data-dependent method consisting in a scan cycle initiated with a full scan of peptide ions in the ultra-high-field Orbitrap analyzer, followed by selection of the precursor with a fixed first mass parameter set at $80 \mathrm{~m} / \mathrm{z}$, high energy collisional dissociation with a normalized energy collision fixed at $33 \mathrm{eV}$ and MS/MS scans on the 20 most abundant precursor ions. Full scan mass spectra were acquired from m/z 350 to 1,800 with an Automatic Gain Control (AGC) target set at 3x10 ions and a resolution of 60,000. MS/MS scans were initiated at a resolution of 15,000 when the ACG target reached $10^{5}$ ions with a threshold intensity of $10^{5}$ and potential charge states of $2+$ and $3+$ after ion selection performed with a dynamic exclusion of $10 \mathrm{~s}$.

\section{Adhesion assays}

Conditioned ECMs were prepared in 96-well plates from subconfluent cell layers. Cells were washed with PBS, detached using $20 \mathrm{mM} \mathrm{NH}_{4} \mathrm{OH}$ and discarded. The remaining ECM layer was washed with PBS, incubated with $1 \%$ BSA (bovine serum albumin) in PBS and washed again. Prior to adhesion assays, cells from additional culture plates were detached with 5 mM EDTA in PBS (HT1080 and HT1080-BMP-1) or collected after spontaneous detachment (HT1080-BMP-1) and rinsed in serum-free medium. After centrifugation, cells were resuspended in serum-free medium and seeded $\left(6.10^{4}\right.$ cells/well) on conditioned ECM. After $45 \mathrm{~min}$ at $37^{\circ} \mathrm{C}$, non-adherent cells were washed with PBS and the extent of adhesion was determined after fixation of adherent cells, staining with $0.1 \%$ crystal violet and absorbance measurements at $570 \mathrm{~nm}$, as described previously (77). A blank value corresponding to BSA-coated wells was subtracted. Alternatively, cells could be seeded in larger wells containing decellularized ECMs for phase contrast imaging. 
To assess adhesion of HT1080 cells on intact and cleaved TSP-1, wells were coated with protein solutions overnight at $4^{\circ} \mathrm{C}$ and saturated with $1 \%$ BSA in PBS. HT1080 cells were prepared and detached from the plates with EDTA, as described above. For competition experiments with TSP-1 and its fragments, cells $\left(4.10^{4}\right.$ cells/well) were mixed with proteins for $1 \mathrm{~h}$ prior to cell adhesion onto TSP-1 coated wells (4 $\mu \mathrm{g}$ TSP-1/well).

\section{ELISA}

96-well Costar culture-treated microtiter plates (also used for adhesion assays) were coated overnight at $4^{\circ} \mathrm{C}$ with $50 \mu 1$ of each protein solution diluted in TBS $(10 \mathrm{mM}$ Tris- $\mathrm{HCl} \mathrm{pH} 8,0.15 \mathrm{M} \mathrm{NaCl})$ with $5 \mathrm{mM} \mathrm{CaCl}_{2}$. Wells were then blocked with $5 \%$ (w/v) skim milk in TBS and incubated successively with the anti-TSP-1 antibodies MAB3074 (1/1,000) or C9 (1/500) and horse anti-mouse antibody coupled to HRP (Cell Signaling Technology; 1/3,000). 2,2'-azino-bis(3ethylbenzthiazoline-6-sulfonic acid) ammonium salt was used as HRP substrate and color development was measured at $405 \mathrm{~nm}$ after $15 \mathrm{~min}$ in a microtiter plate reader (Tecan Infinite M1000).

\section{Detection of TGF- $\beta$ activity}

TGF- $\beta$ activity was monitored first through the immuno-detection of phosphorylated SMAD2 (P-SMAD2). 100,000 HT1080 cells or 30,000 keratocytes were grown in 12-well plates with $1 \mathrm{~mL}$ complete medium for $48 \mathrm{~h}$. Solutions containing TSP-1 (beforehand incubated or not with active or inactive BMP-1) and control conditions (in $100 \mu \mathrm{l})$ were then added to the cells for 30 min (keratocytes) or $1 \mathrm{~h}$ (HT1080 cells). For the experiments with LTGF- $\beta$, cells were first washed with PBS and the medium was replaced by DMEM without serum before the addition of LTGF- $\beta$ (17.5 nM, preincubated for $15 \mathrm{~min}$ at $37^{\circ} \mathrm{C}$ with a 3-molar excess of TSP-1 or fragment 1 or at room temperature with $10 \mathrm{mM} \mathrm{HCl}$ ) or control solutions. At the end of the cell treatment time, cell supernatants were discarded, cells were washed with cold PBS and cell lysates were collected in RIPA buffer (50 mM Tris $\mathrm{pH}$ 8, $0.15 \mathrm{M} \mathrm{NaCl}, 1 \% \mathrm{NP}-40,0.5 \%$ sodium deoxycholate and $0.1 \%$ SDS) containing protease (Complete, Roche) and phosphatase (PhosSTOP, Roche) inhibitors. $20 \mu \mathrm{g}$ of total protein/lane (Bradford assay) were loaded on gels for immunoblotting for P-SMAD2, SMAD2 or actin. 
TGF- $\beta$ activity was also assessed through a reporter gene assay, as previously described (31). In this experiment, 50,000 HT1080 cells were seeded in 24-well plates with DMEM + $10 \%$ FCS. After 24 h, they were co-transfected with (i) the pGL3-basic reporter plasmid (Promega) encoding firefly luciferase under the control of 9 repeats of a SMAD-binding element ((CAGA)9-Luc) and (ii) the phRLCMV vector (Promega) encoding Renilla luciferase under the control of the cytomegalovirus ubiquitous promoter, in order to determine the transfection efficiency and to normalize luciferase values. The following day, samples containing TSP-1 (incubated or not with active or inactive BMP-1) and control conditions were added for $24 \mathrm{~h}$. Proteins were then extracted from HT1080 cells in Passive Lysis Buffer (Promega) and transcriptional responses were measured with the Dual-Luciferase Reporter Assay System (Promega).

\section{Human corneas}

Four corneal samples from patients presenting permanent stromal scars were collected at the time of corneal transplantation, according to the tenets of the declaration of Helsinki. Patient 1 (male, age 23) had his cornea perforated by broken glass 17 months prior to surgery. Patient 2 (male, age 66) had a handiwork accident 6 months before surgery. Patient 3 (male, age 68) suffered from a corneal ulcer since 2 years. Patient 4 (male, age 50) was injured by a perforating metal foreign body more than 2 years before. Corneas were frozen at $-80^{\circ} \mathrm{C}$ after surgery before being processed for immunoblotting. In brief, frozen corneas were ground in a mortar, homogenized in Laemmli buffer and boiled at $100^{\circ} \mathrm{C}$ for $10 \mathrm{~min}$. After centrifugation at 15,000 g for $15 \mathrm{~min}$, the supernatant was collected and analyzed on a stain-free 4-20\% TGX precast gel (Biorad) to allow total protein relative quantification. Equivalent amounts of total protein for each human cornea were then analyzed by immunoblotting and compared to known amounts of keratocyte conditioned medium. Before detection, the membrane was split into two parts and two different exposure times were used to reveal full-length TSP-1 (7 s) and fragment 1 (4 min).

\section{Mouse ex vivo model of corneal wound healing}

Mouse corneas were dissected from 13 week-old male C57B1/6JRj mice (Janvier Labs). After eye washing with 5\% povidone-iodine alcoholic solution (MEDA Pharma) and $0.09 \% \mathrm{NaCl}$ (Aguettant), dissection of mouse corneas was 
performed with an ophthalmic knife and Vannas scissors under a binocular magnifier. Corneas were then washed in 4 bathes of culture medium without serum (DMEM/Ham's F12 (1:1), $50 \mu \mathrm{g} / \mathrm{mL}$ sodium ascorbate and $2 \%$ antibiotic/antimycotic solution) and wounded in the center with disposable $1 \mathrm{~mm}$-diameter biopsy punches (Integra Miltex). Wounded corneas were distributed in the wells of a 96-well plate containing $200 \mu 1$ of the same medium as above with $10 \%$ iron-supplemented calf serum and maintained in a humid atmosphere at $37^{\circ} \mathrm{C}$ with $5 \% \mathrm{CO}_{2}$. At days 2 and 4, cleaved TSP-1 was prepared by incubating $450 \mathrm{nM}$ TSP-1 with $356 \mathrm{nM} \mathrm{BMP}-1$ for $4 \mathrm{~h}$ at $37^{\circ} \mathrm{C}$ in the buffer described above for all cleavage assays ("vehicle"). Controls with TSP-1 alone and BMP-1 alone were also prepared. Cornea medium was changed on days 2 and 4 with a progressive reduction in serum concentration to $2 \%$ (day 2) and $0 \%$ (day 4) and incubations were added to represent $10 \%$ of the volume in each well (45 nM final TSP-1 concentration). Additional corneas were also treated with $10 \mathrm{ng} / \mathrm{ml} \mathrm{TGF}-\beta$ or cleaved TSP- $1+10 \mu \mathrm{M} \mathrm{SB} 431542$. Bright field images were taken every day with a Zeiss Primovert or Nikon Ti-E microscope and used to measure the diameter of the wound with FIJI. On day 7, the corneas were fixed overnight in buffered $4 \%$ paraformaldehyde and embedded in paraffin wax. Two sections of $5 \mu \mathrm{m} /$ cornea corresponding to two opposite wound borders were prepared (see Fig. 8C) and stained with the anti- $\alpha$-SMA antibody Ab5694 (AbCam; 1/100 in $3 \%$ BSA) after dewaxing and rehydration. The secondary antibody was a goat anti-rabbit antibody coupled to Alexa Fluor 555 (A-21428 from Thermo Scientific; 1/350 in 0.2 \% BSA). Corneal sections were counterstained with DAPI and examined with a Nikon Ti-E fluorescence microscope. $\alpha$-SMApositive cells were counted in 3-4 fields/cornea.

\section{Statistical analysis}

All statistical analyses were performed using the GraphPad Prism 7 or 8 software. Unless otherwise stated, experimental values for the different conditions were compared using one-way ANOVA and Tukey post-ANOVA test. Data were tested for normality with the Shapiro-Wilk test and for equality of variances with the Brown-Forsythe test. * $: p$-value < $0.05 ; * *: p$-value $<0.01 ; * * *: p$-value $<0.001 ; * * * *$ : p-value $<10^{-4}$.

\section{SUPPLEMENTARY MATERIALS}

Fig. S1. Effect of BMP-1 on cell adhesion and apoptosis. 
Fig. S2. BMP-1 alters cell adhesion through ECM modification.

Fig. S3. Characterization of TSP-1 fragments with various antibodies against the C-terminal and N-terminal domains of TSP-1.

Fig. S4. Mass spectrum and attribution of $\mathrm{b}$ and $\mathrm{y}$ ions for peptide 376-402 of human platelet TSP-1 defining BMP-1 cleavage site.

Fig. S5. Quantification of TSP-1 knockdown efficiency.

Fig. S6. Efficiency of coating 96-well plates with intact and cleaved TSP-1.

Fig. S7. SDS-PAGE analysis of purified fragment 1 and semi-purified fragment 2 in non-reducing and reducing conditions.

Fig. S8. Alignment of TSP-1 from 12 species and human TSP-2 around the BMP-1 cleavage site.

References $(78,79)$

Movie S1. Time lapse recording of subconfluent HT1080 cells.

Movie S2. Time lapse recording of the morphological changes preceding cell detachment in subconfluent HT1080-BMP1 cells. 


\section{REFERENCES AND NOTES}

1. S. A. Goodman, R. Albano, F. C. Wardle, G. Matthews, D. Tannahill, L. Dale, BMP1-related metalloproteinases promote the development of ventral mesoderm in early Xenopus embryos. Dev. Biol. 195, 144-157 (1998).

2. G. Marques, M. Musacchio, M. J. Shimell, K. Wunnenberg-Stapleton, K. W. Cho, M. B. O'Connor, Production of a DPP activity gradient in the early Drosophila embryo through the opposing actions of the SOG and TLD proteins. Cell 91, 417426 (1997).

3. N. Suzuki, P. A. Labosky, Y. Furuta, L. Hargett, R. Dunn, A. B. Fogo, K. Takahara, D. M. Peters, D. S. Greenspan, B. L. Hogan, Failure of ventral body wall closure in mouse embryos lacking a procollagen C-proteinase encoded by Bmp1, a mammalian gene related to Drosophila tolloid. Development 122, 3587-3595 (1996).

4. T. G. Clark, S. J. Conway, I. C. Scott, P. A. Labosky, G. Winnier, J. Bundy, B. L. Hogan, D. S. Greenspan, The mammalian Tolloid-like 1 gene, TII1, is necessary for normal septation and positioning of the heart. Development 126, 2631-2642 (1999).

5. D. Syx, B. Guillemyn, S. Symoens, A. B. Sousa, A. Medeira, M. Whiteford, T. Hermanns-Le, P. J. Coucke, A. De Paepe, F. Malfait, Defective proteolytic processing of fibrillar procollagens and prodecorin due to biallelic BMP1 mutations results in a severe, progressive form of Osteogenesis Imperfecta. J. Bone Miner. Res. 30, 1445-1456 (2015).

6. A. M. Muir, D. Massoudi, N. Nguyen, D. R. Keene, S. J. Lee, D. E. Birk, J. M. Davidson, M. P. Marinkovich, D. S. Greenspan, BMP1-like proteinases are essential to the structure and wound healing of skin. Matrix Biol. 56, 114-131 (2016).

7. A. M. Muir, Y. Ren, D. H. Butz, N. A. Davis, R. D. Blank, D. E. Birk, S. J. Lee, D. Rowe, J. Q. Feng, D. S. Greenspan, Induced ablation of Bmp1 and TIl1 produces osteogenesis imperfecta in mice. Hum. Mol. Genet. 23, 3085-3101 (2014).

8. J. Wang, D. Massoudi, Y. Ren, A. M. Muir, S. E. Harris, D. S. Greenspan, J. Q. Feng, BMP1 and TLL1 are required for maintaining periodontal homeostasis. J. Dent. Res. 96, 578-585 (2017).

9. N. M. Wolfman, A. C. McPherron, W. N. Pappano, M. V. Davies, K. Song, K. N. Tomkinson, J. F. Wright, L. Zhao, S. M. Sebald, D. S. Greenspan, S. J. Lee, Activation of latent myostatin by the BMP-1/tolloid family of metalloproteinases. Proc. Natl. Acad. Sci. U.S.A 100, 15842-15846 (2003).

10. F. Malecaze, D. Massoudi, P. Fournie, C. Tricoire, M. Cassagne, M. Malbouyres, D. J. Hulmes, C. Moali, S. D. Galiacy, Upregulation of bone morphogenetic protein-1/mammalian tolloid and procollagen C-proteinase enhancer-1 in corneal scarring. Invest. Ophthalmol. Vis. Sci. 55, 6712-6721 (2014).

11. E. Sanchez-Sabate, L. Alvarez, E. Gil-Garay, L. Munuera, N. Vilaboa, Identification of differentially expressed genes in trabecular bone from the iliac crest of osteoarthritic patients. Osteoarthritis Cartilage 17, 1106-1114 (2009).

12. J. Beaumont, B. Lopez, N. Hermida, B. Schroen, G. San Jose, S. Heymans, F. Valencia, J. J. Gomez-Doblas, E. De Teresa, J. Diez, A. Gonzalez, microRNA-122 down-regulation may play a role in severe myocardial fibrosis in human aortic stenosis through TGF-beta1 up-regulation. Clin. Sci. 126, 497-506 (2014).

13. J. Friebel, A. Weithauser, M. Witkowski, B. H. Rauch, K. Savvatis, A. Dorner, T. Tabaraie, M. Kasner, V. Moos, D. Bosel, M. Gotthardt, M. H. Radke, M. Wegner, P. Bobbert, D. Lassner, C. Tschope, H. P. Schutheiss, S. B. Felix, U. Landmesser, U. Rauch, Protease-activated receptor 2 deficiency mediates cardiac fibrosis and diastolic dysfunction. Eur. Heart J. 40, 33183332 (2019).

14. B. Lopez, A. Gonzalez, J. Beaumont, R. Querejeta, M. Larman, J. Diez, Identification of a potential cardiac antifibrotic mechanism of torasemide in patients with chronic heart failure. J. Am. Coll. Cardiol. 50, 859-867 (2007).

15. A. Borazjani, N. Kow, S. Harris, B. Ridgeway, M. S. Damaser, Transcriptional Regulation of Connective Tissue Metabolism Genes in Women With Pelvic Organ Prolapse. Female Pelvic Med. Reconstr. Surg. 23, 44-52 (2017).

16. J. Fuentes-Duculan, K. M. Bonifacio, M. Suarez-Farinas, N. Kunjravia, S. Garcet, T. Cruz, C. Q. F. Wang, H. Xu, P. Gilleadeau, M. Sullivan-Whalen, M. H. Tirgan, J. G. Krueger, Aberrant connective tissue differentiation towards cartilage and bone underlies human keloids in African Americans. Exp. Dermatol. 26, 721-727 (2017).

17. P. Perimenis, T. Bouckenooghe, J. Delplanque, E. Moitrot, E. Eury, S. Lobbens, P. Gosset, L. Devisme, B. Duvillie, A. Abderrahmani, L. Storme, P. Fontaine, P. Froguel, A. Vambergue, Placental antiangiogenic prolactin fragments are increased in human and rat maternal diabetes. Biochim. Biophys. Acta 1842, 1783-1793 (2014).

18. A. Naba, K. R. Clauser, J. M. Lamar, S. A. Carr, R. O. Hynes, Extracellular matrix signatures of human mammary carcinoma identify novel metastasis promoters. Elife. 3, e01308 (2014). 
19. R. da Silva, M. Uno, S. K. Marie, S. M. Oba-Shinjo, LOX expression and functional analysis in astrocytomas and impact of IDH1 mutation. PLoS One 10, e0119781 (2015).

20. Y. Y. Hsieh, S. Y. Tung, H. Y. Pan, C. W. Yen, H. W. Xu, Y. F. Deng, Y. J. Lin, W. T. Hsu, C. S. Wu, C. Li, Upregulation of bone morphogenetic protein 1 is associated with poor prognosis of late-stage gastric Cancer patients. BMC Cancer 18, 508 (2018).

21. W. Xiao, X. Wang, T. Wang, J. Xing, Overexpression of BMP1 reflects poor prognosis in clear cell renal cell carcinoma. Cancer Gene Ther., (2019).

22. J. S. Bond, R. J. Beynon, The astacin family of metalloendopeptidases. Protein Sci. 4, 1247-1261 (1995).

23. R. Berry, T. A. Jowitt, J. Ferrand, M. Roessle, J. G. Grossmann, E. G. Canty-Laird, R. A. Kammerer, K. E. Kadler, C. Baldock, Role of dimerization and substrate exclusion in the regulation of bone morphogenetic protein-1 and mammalian tolloid. Proc. Natl. Acad. Sci. U.S.A 106, 8561-8566 (2009).

24. C. Wermter, M. Howel, V. Hintze, B. Bombosch, K. Aufenvenne, I. Yiallouros, W. Stocker, The protease domain of procollagen C-proteinase (BMP1) lacks substrate selectivity, which is conferred by non-proteolytic domains. Biol. Chem. 388, 513-521 (2007).

25. C. Moali, D. J. Hulmes, in Extracellular Matrix : Pathobiology and Signaling, M. Karamanos, Ed. (De Gruyter, Berlin, 2012), pp. 539-561.

26. S. Vadon-Le Goff, D. J. Hulmes, C. Moali, BMP-1/tolloid-like proteinases synchronize matrix assembly with growth factor activation to promote morphogenesis and tissue remodeling. Matrix Biol. 44-46C, 14-23 (2015).

27. P. Blader, S. Rastegar, N. Fischer, U. Strahle, Cleavage of the BMP-4 antagonist chordin by zebrafish tolloid. Science 278, 1937-1940 (1997).

28. G. Ge, D. R. Hopkins, W. B. Ho, D. S. Greenspan, GDF11 forms a bone morphogenetic protein 1-activated latent complex that can modulate nerve growth factor-induced differentiation of PC12 cells. Mol. Cell Biol. 25, 5846-5858 (2005).

29. B. Kim, G. Huang, W. B. Ho, D. S. Greenspan, Bone Morphogenetic Protein-1 Processes Insulin-like Growth Factor-binding Protein 3. J. Biol. Chem. 286, 29014-29025 (2011).

30. G. Szlama, V. Vasarhelyi, M. Trexler, L. Patthy, Influence of WFIKKN1 on BMP1-mediated activation of latent myostatin. FEBS J. 283, 4515-4527 (2016).

31. F. Delolme, C. Anastasi, L. B. Alcaraz, V. Mendoza, S. Vadon-Le Goff, M. Talantikite, R. Capomaccio, J. Mevaere, L. Fortin, D. Mazzocut, O. Damour, I. Zanella-Cleon, D. J. Hulmes, C. M. Overall, U. Valcourt, F. Lopez-Casillas, C. Moali, Proteolytic control of TGF-beta co-receptor activity by BMP-1/tolloid-like proteases revealed by quantitative iTRAQ proteomics. Cell. Mol. Life Sci. 72, 1009-1027 (2015).

32. G. Ge, D. S. Greenspan, BMP1 controls TGFbeta1 activation via cleavage of latent TGFbeta-binding protein. J. Cell Biol. 175, $111-120$ (2006).

33. S. Banerjee, R. J. Andrew, C. J. Duff, K. Fisher, C. D. Jackson, C. B. Lawrence, N. Maeda, D. S. Greenspan, K. A. B. Kellett, N. M. Hooper, Proteolysis of the low density lipoprotein receptor by bone morphogenetic protein-1 regulates cellular cholesterol uptake. Sci. Rep. 9, 11416 (2019).

34. P. Chau, P. E. Fielding, C. J. Fielding, Bone morphogenetic protein-1 (BMP-1) cleaves human proapolipoprotein A1 and regulates its activation for lipid binding. Biochemistry 46, 8445-8450 (2007).

35. S. E. Heumuller, M. Talantikite, M. Napoli, J. Armengaud, M. Morgelin, U. Hartmann, G. Sengle, M. Paulsson, C. Moali, R. Wagener, C-terminal proteolysis of the collagen VI alpha3 chain by BMP-1 and proprotein convertase(s) releases endotrophin in fragments of different sizes. J. Biol. Chem. 294, 13769-13780 (2019).

36. L. Garrigue-Antar, N. Hartigan, K. E. Kadler, Post-translational modification of bone morphogenetic protein-1 is required for secretion and stability of the protein. J. Biol. Chem. 277, 43327-43334 (2002).

37. C. Moali, B. Font, F. Ruggiero, D. Eichenberger, P. Rousselle, V. Francois, A. Oldberg, L. Bruckner-Tuderman, D. J. Hulmes, Substrate-specific modulation of a multisubstrate proteinase. C-terminal processing of fibrillar procollagens is the only BMP-1-dependent activity to be enhanced by PCPE-1. J. Biol. Chem. 280, 24188-24194 (2005).

38. I. C. Scott, I. L. Blitz, W. N. Pappano, Y. Imamura, T. G. Clark, B. M. Steiglitz, C. L. Thomas, S. A. Maas, K. Takahara, K. W. Cho, D. S. Greenspan, Mammalian BMP-1/Tolloid-related metalloproteinases, including novel family member mammalian Tolloid-like 2, have differential enzymatic activities and distributions of expression relevant to patterning and skeletogenesis. Dev. Biol. 213, 283-300 (1999).

39. M. Talantikite, P. Lecorche, F. Beau, O. Damour, C. Becker-Pauly, W. B. Ho, V. Dive, S. Vadon-Le Goff, C. Moali, Inhibitors of BMP-1/tolloid-like proteinases: efficacy, selectivity and cellular toxicity. FEBS Open Bio 8, 2011-2021 (2018). 
40. C. Bijakowski, S. Vadon-Le Goff, F. Delolme, J. M. Bourhis, P. Lecorche, F. Ruggiero, C. Becker-Pauly, I. Yiallouros, W. Stocker, V. Dive, D. J. Hulmes, C. Moali, Sizzled is unique among secreted frizzled-related proteins for its ability to specifically inhibit bone morphogenetic protein-1 (BMP-1)/tolloid-like proteinases. J. Biol. Chem. 287, 33581-33593 (2012).

41. H. X. Lee, A. L. Ambrosio, B. Reversade, E. M. De Robertis, Embryonic dorsal-ventral signaling: secreted frizzled-related proteins as inhibitors of tolloid proteinases. Cell 124, 147-159 (2006).

42. D. S. Annis, J. E. Murphy-Ullrich, D. F. Mosher, Function-blocking antithrombospondin-1 monoclonal antibodies. J. Thromb. Haemost. 4, 459-468 (2006).

43. A. Doucet, C. M. Overall, Broad coverage identification of multiple proteolytic cleavage site sequences in complex high molecular weight proteins using quantitative proteomics as a complement to edman sequencing. Mol. Cell Proteomics. 10, M110.003533 (2011).

44. J. Hofsteenge, K. G. Huwiler, B. Macek, D. Hess, J. Lawler, D. F. Mosher, J. Peter-Katalinic, C-mannosylation and Ofucosylation of the thrombospondin type 1 module. J. Biol. Chem. 276, 6485-6498 (2001).

45. J. C. Adams, J. Lawler, The thrombospondins. Cold Spring Harb. Perspect. Biol. 3, a009712 (2011).

46. C. A. Elzie, J. E. Murphy-Ullrich, The N-terminus of thrombospondin: the domain stands apart. Int. J. Biochem. Cell Biol. 36, 1090-1101 (2004).

47. J. C. Adams, A. A. Bentley, M. Kvansakul, D. Hatherley, E. Hohenester, Extracellular matrix retention of thrombospondin 1 is controlled by its conserved C-terminal region. J. Cell Sci. 121, 784-795 (2008).

48. D. J. Kim, E. D. Christofidou, D. R. Keene, M. Hassan Milde, J. C. Adams, Intermolecular interactions of thrombospondins drive their accumulation in extracellular matrix. Mol. Biol. Cell. 26, 2640-2654 (2015).

49. J. E. Murphy-Ullrich, M. J. Suto, Thrombospondin-1 regulation of latent TGF-beta activation: A therapeutic target for fibrotic disease. Matrix Biol. 68-69, 28-43 (2018).

50. M. Matsuba, A. E. Hutcheon, J. D. Zieske, Localization of thrombospondin-1 and myofibroblasts during corneal wound repair. Exp. Eye Res. 93, 534-540 (2011).

51. H. Janin-Manificat, M. R. Rovere, S. D. Galiacy, F. Malecaze, D. J. Hulmes, C. Moali, O. Damour, Development of ex vivo organ culture models to mimic human corneal scarring. Mol. Vis. 18, 2896-2908 (2012).

52. N. J. Laping, E. Grygielko, A. Mathur, S. Butter, J. Bomberger, C. Tweed, W. Martin, J. Fornwald, R. Lehr, J. Harling, L. Gaster, J. F. Callahan, B. A. Olson, Inhibition of transforming growth factor (TGF)-beta1-induced extracellular matrix with a novel inhibitor of the TGF-beta type I receptor kinase activity: SB-431542. Mol. Pharmacol 62, 58-64 (2002).

53. B. Barrientez, S. E. Nicholas, A. Whelchel, R. Sharif, J. Hjortdal, D. Karamichos, Corneal injury: Clinical and molecular aspects. Exp. Eye Res. 186, 107709 (2019).

54. J. Dubail, F. Kesteloot, C. Deroanne, P. Motte, V. Lambert, J. M. Rakic, C. Lapiere, B. Nusgens, A. Colige, ADAMTS-2 functions as anti-angiogenic and anti-tumoral molecule independently of its catalytic activity. Cell. Mol. Life Sci. 67, 42134232 (2010).

55. N. M. Moss, M. V. Barbolina, Y. Liu, L. Sun, H. G. Munshi, M. S. Stack, Ovarian cancer cell detachment and multicellular aggregate formation are regulated by membrane type 1 matrix metalloproteinase: a potential role in I.p. metastatic dissemination. Cancer Res. 69, 7121-7129 (2009).

56. H. Chen, M. E. Herndon, J. Lawler, The cell biology of thrombospondin-1. Matrix Biol. 19, 597-614 (2000).

57. J. C. Adams, J. Lawler, Diverse mechanisms for cell attachment to platelet thrombospondin. J. Cell Sci. 104 1061-1071 (1993).

58. A. S. Asch, J. Tepler, S. Silbiger, R. L. Nachman, Cellular attachment to thrombospondin. Cooperative interactions between receptor systems. J. Biol. Chem. 266, 1740-1745 (1991).

59. D. D. Roberts, J. A. Sherwood, V. Ginsburg, Platelet thrombospondin mediates attachment and spreading of human melanoma cells. J. Cell Biol. 104, 131-139 (1987).

60. C. Y. Chen, E. Melo, P. Jakob, A. Friedlein, B. Elsasser, P. Goettig, V. Kueppers, F. Delobel, C. Stucki, T. Dunkley, S. Fauser, O. Schilling, R. lacone, N-Terminomics identifies HtrA1 cleavage of thrombospondin-1 with generation of a proangiogenic fragment in the polarized retinal pigment epithelial cell model of age-related macular degeneration. Matrix Biol. 70, 84-101 (2018).

61. K. Seif, L. Alidzanovic, B. Tischler, N. Ibrahim, B. Zagrapan, S. Rauscher, M. Salzmann, L. Hell, L. M. Mauracher, U. Budde, J. A. Schmid, B. Jilma, I. Pabinger, A. Assinger, P. Starlinger, C. Brostjan, Neutrophil-Mediated Proteolysis of Thrombospondin1 Promotes Platelet Adhesion and String Formation. Thromb. Haemost. 118, 2074-2085 (2018). 
62. L. M. Silva, T. Kryza, T. Stoll, C. Hoogland, Y. Dong, C. R. Stephens, M. L. Hastie, V. Magdolen, O. Kleifeld, J. J. Gorman, J. A. Clements, Integration of Two In-depth Quantitative Proteomics Approaches Determines the Kallikrein-related Peptidase 7 (KLK7) Degradome in Ovarian Cancer Cell Secretome. Mol. Cell. Proteomics 18, 818-836 (2019).

63. P. R. Lawler, J. Lawler, Molecular basis for the regulation of angiogenesis by thrombospondin-1 and -2 . Cold Spring Harb. Perspect. Med. 2, a006627 (2012).

64. B. St Croix, C. Rago, V. Velculescu, G. Traverso, K. E. Romans, E. Montgomery, A. Lal, G. J. Riggins, C. Lengauer, B. Vogelstein, K. W. Kinzler, Genes expressed in human tumor endothelium. Science 289, 1197-1202 (2000).

65. Y. Tong, M. Wang, Y. Dai, D. Bao, J. Zhang, H. Pan, LncRNA HOXA-AS3 Sponges miR-29c to Facilitate Cell Proliferation, Metastasis, and EMT Process and Activate the MEK/ERK Signaling Pathway in Hepatocellular Carcinoma. Hum. Gene Ther. Clin. Dev. 30, 129-141 (2019).

66. X. Wu, T. Liu, O. Fang, L. J. Leach, X. Hu, Z. Luo, miR-194 suppresses metastasis of non-small cell lung cancer through regulating expression of BMP1 and p27(kip1). Oncogene 33, 1506-1514 (2014).

67. N. V. Lee, M. Sato, D. S. Annis, J. A. Loo, L. Wu, D. F. Mosher, M. L. Iruela-Arispe, ADAMTS1 mediates the release of antiangiogenic polypeptides from TSP1 and 2. EMBO J. 25, 5270-5283 (2006).

68. S. Goicoechea, A. W. Orr, M. A. Pallero, P. Eggleton, J. E. Murphy-Ullrich, Thrombospondin mediates focal adhesion disassembly through interactions with cell surface calreticulin. J. Biol. Chem. 275, 36358-36368 (2000).

69. S. Rosini, N. Pugh, A. M. Bonna, D. J. S. Hulmes, R. W. Farndale, J. C. Adams, Thrombospondin-1 promotes matrix homeostasis by interacting with collagen and lysyl oxidase precursors and collagen cross-linking sites. Sci. Signal. 11, (2018).

70. M. Shi, J. Zhu, R. Wang, X. Chen, L. Mi, T. Walz, T. A. Springer, Latent TGF-beta structure and activation. Nature 474, 343349 (2011).

71. G. Blanc, B. Font, D. Eichenberger, C. Moreau, S. Ricard-Blum, D. J. Hulmes, C. Moali, Insights into how CUB domains can exert specific functions while sharing a common fold: Conserved and specific features of the CUB1 domain contribute to the molecular basis of procollagen C-proteinase enhancer-1 activity. J. Biol. Chem. 282, 16924-16933 (2007).

72. C. W. Hung, T. Koudelka, C. Anastasi, A. Becker, C. Moali, A. Tholey, Characterization of post-translational modifications in full-length human BMP-1 confirms the presence of a rare vicinal disulfide linkage in the catalytic domain and highlights novel features of the EGF domain. J. Proteomics 138, 136-145 (2016).

73. K. O. Yee, M. Duquette, A. Ludlow, J. Lawler, Purification and analysis of thrombospondin-1. Curr. Protoc. Cell Biol. Chapter 10, Unit 10.10 (2003).

74. E. Turtle, N. Chow, C. Yang, S. Sosa, U. Bauer, M. Brenner, D. Solow-Cordero, W. B. Ho, Design and synthesis of procollagen C-proteinase inhibitors. Bioorg. Med. Chem. Lett. 22, 7397-7401 (2012).

75. J. Schindelin, I. Arganda-Carreras, E. Frise, V. Kaynig, M. Longair, T. Pietzsch, S. Preibisch, C. Rueden, S. Saalfeld, B. Schmid, J. Y. Tinevez, D. J. White, V. Hartenstein, K. Eliceiri, P. Tomancak, A. Cardona, Fiji: an open-source platform for biologicalimage analysis. Nat. Methods 9, 676-682 (2012).

76. G. Klein, C. Mathe, M. Biola-Clier, S. Devineau, E. Drouineau, E. Hatem, L. Marichal, B. Alonso, J. C. Gaillard, G. Lagniel, J. Armengaud, M. Carriere, S. Chedin, Y. Boulard, S. Pin, J. P. Renault, J. C. Aude, J. Labarre, RNA-binding proteins are a major target of silica nanoparticles in cell extracts. Nanotoxicology 10, 1555-1564 (2016).

77. S. Bachy, F. Letourneur, P. Rousselle, Syndecan-1 interaction with the LG4/5 domain in laminin-332 is essential for keratinocyte migration. J. Cell. Physiol. 214, 238-249 (2008).

78. X. Robert, P. Gouet, Deciphering key features in protein structures with the new ENDscript server. Nucleic Acids Res. 42, W320-324 (2014)

79. F. Sievers, A. Wilm, D. Dineen, T. J. Gibson, K. Karplus, W. Li, R. Lopez, H. McWilliam, M. Remmert, J. Soding, J. D. Thompson, D. G. Higgins, Fast, scalable generation of high-quality protein multiple sequence alignments using Clustal Omega. Mol. Syst. Biol. 7, 539 (2011). 
Acknowledgements: We are grateful to Joanne Murphy-Ullrich (UAB, Birmingham) for very useful tips on how to handle thrombospondin-1, to Claire Lethias (LBTI, Lyon) for providing most of the antibodies used in the preliminary screening of candidate substrates, to Dominique Sigaudo-Roussel and her group for helping us during cornea dissection and to David Hulmes (LBTI, Lyon) for critical reading of the manuscript. We also thank the staff of the LYMIC-

PLATIM, ANIRA-CYTOMETRY and PSF facilities from the SFR Biosciences (UMS 3444, Lyon) for their help in performing flow cytometry, microscopy and automated Edman sequencing experiments respectively. Finally, we thank Claire Bardel (UMR 5558 CNRS-University of Lyon) for guiding us on how to perform statistical analyses. Funding: This work was supported by the CNRS, the University of Lyon, the Région Auvergne Rhône-Alpes (ARC 2013 to M.T. and C.M.), the ANR-07-PHYSIO-022-01 and ANR-18-CE92-0035-01 to C.M., the ANR-13-RPIB-0003-01 to P.R., the Ligue Nationale contre le Cancer (to L.B.A and P.R.) and the Ligue contre le Cancer-Comité du Rhône (to U.V.). Author contributions: C.M. and P.R. designed the project. C. Anastasi, P.R., M.T., A.T., C.C., A.B., N.M., M.D., L.B.A., L.F., A.A, F.D., N.E.K., J.A., C. Auxenfans, S.V.L.G and C.M. performed experiments. C. Auxenfans and P.F. collected and provided human primary cells and corneas. C.M., P.R., C. Anastasi, C.C., M.D., S.V.L.G, F.D. and U.V. analyzed the data. C.M. wrote the manuscript. Competing interests: The authors declare that they have no competing interests. Data and Materials Availability: All data needed to evaluate the conclusions in the paper are present in the paper or the Supplementary Materials. 


\section{FIGURE LEGENDS}

Fig. 1. Changes in cell adhesion induced by BMP-1 cleavage of ECM proteins. (A) Phase contrast images of subconfluent 293-EBNA cells stably transfected with empty vector or a BMP-1-encoding vector, in the absence or presence of the BMP-1 inhibitor hydroxamate $(\mathrm{Hxt})$. Images are representative of $n=3$ independent experiments. Scale bar, $150 \mu \mathrm{m}$. (B) Percentage of adherent and detached subconfluent 293-EBNA cells expressing empty vector or BMP-1 over time after serum deprivation. Data from 1 of 2 independent experiments are presented as a percentage of total cells at the $0 \mathrm{~h}$ time point, and error bars represent SD of measurements from 6 technical replicates per group. Data from the other independent experiment are shown in fig. S1A. (C) Immunoblotting for BMP-1 (arrowhead) in the medium and ECM of 293-EBNA cells expressing empty vector or BMP-1. The four non-contiguous lanes belong to the same blot and are representative of $n=3$ independent experiments for medium and $n=2$ independent experiments for ECM. (D) Phase contrast images of HT1080-E94A and HT1080-BMP-1 cells at increasing cell densities, showing the morphological changes preceding the loss of cell adhesion. For comparison, parental HT1080 cells and HT1080-BMP-1 cells grown in the presence of the BMP-1 inhibitor sizzled (Szl) are also shown. Images are representative of $n=4$ independent experiments. Scale bar, $50 \mu \mathrm{m}$. (E) Fluorescence imaging showing actin (phalloidin, green) and nuclei (blue) in HT1080, HT1080-BMP-1, and HT1080-E94A cells at intermediate cell density. Images are representative of $\mathrm{n}=3$ independent experiments. Scale bars, 50 mm. (F) Mean cell area of HT1080, HT1080-BMP-1, and HT1080-E94A cells measured using images taken as described in (E). The graph shows means of cell area $\pm 95 \%$ confidence interval from 3 independent experiments (15 fields analyzed per condition per experiment). Conditions were compared using the test of Kruskal-Wallis with Dunn's multiple comparison test. (G) Adhesion of HT1080 and HT1080-BMP-1 cells on decellularized ECM deposited by the same cells. Prior to the assay, the HT1080 cells to be tested were detached from culture plates with EDTA, and the HT1080-BMP-1 cells were either detached with EDTA (w EDTA) or collected after spontaneous detachment (w/o EDTA). Data show means \pm SD of $n=3$ independent experiments. (H) Phase contrast images of parental HT1080 cells seeded, in the absence of serum, on the decellularized ECM of HT1080, HT1080-E94A, or HT1080-BMP-1 cells after 3.5 h. Scale bar, $50 \mu$ m. Images are representative of $n=2$ independent experiments. 
Fig. 2. TSP-1 is cleaved by BMP-1. (A) Immunoblotting for TSP-1 and one of its proteolytic products in the conditioned medium of HT1080 (-) and HT1080-BMP-1 (+) cells at different time points after serum starvation (non-reducing conditions). A similar product is observed when purified human TSP-1 is incubated with recombinant BMP-1 (in vitro). Blot is representative of $n=5$ independent experiments. (B) Immunoblotting for TSP-1 in the conditioned medium of HT1080-BMP-1 cells treated with $0(-), 1(+)$, or 5 (++) $\mu \mathrm{M}$ of the BMP-1 inhibitor Hxt and collected after $15 \mathrm{~h}$ (nonreducing conditions). Blot is representative of $n=3$ independent experiments. (C) Immunoblotting for TSP-1 in the conditioned medium of 293-EBNA cells transfected with an empty vector (-) or a vector encoding BMP-1 (+) (nonreducing conditions). Medium was collected $9 \mathrm{~h}$ after serum starvation. Blot is representative of $\mathrm{n}=6$ independent experiments. (D) Domain structure of TSP-1, antibody epitopes, and positions of cleavage sites for BMP-1, thrombin, cathepsin G, HtrA1, KLK7 and ADAMTS-1. TSPN, Thrombospondin N-terminal; VWFC, Von Willebrand Factor type C; TSR, Thrombospondin type 1 repeats; EGF, Epidermal growth factor; C-ter, Thrombospondin C-terminal domain. (E) Analysis of TSP-1 cleavage at increasing BMP-1:TSP-1 ratios for the indicated incubation times under reducing (+DTT) and non-reducing (-DTT) conditions. \# indicates the position of BMP-1. Image is representative of $\mathrm{n}=2$ independent experiments. (F) Immunoblotting for TSP-1 in the conditioned medium of 293-EBNA cells collected as in (C) (nonreducing conditions) and comparison with TSP1 cleaved in vitro by BMP-1. Blot is representative of $n=4$ independent experiments.

Fig. 3. The C-terminal fragment of TSP-1 is released from the ECM. (A) Immunostaining of HT1080, HT1080-BMP1, and HT1080-E94A cells with antibodies specific for TSP-1 (MAB3074) and fibronectin (FN). Nuclei are labelled with DAPI. Scale bar, $20 \mu \mathrm{m}$. Images are representative of $\mathrm{n}=3$ independent experiments. (B) Immunoblotting for TSP-1 in the ECM of HT1080 or 293-EBNA cells transfected with an empty vector (-), a vector encoding the E94A mutant form of BMP-1 (*), or a vector encoding BMP-1 (+) under non-reducing conditions. Antibody MAB3074 recognizes TSP-1 domains located downstream of the BMP-1 cleavage site; antibody C9 recognizes TSP-1 domains located upstream of the BMP-1 cleavage site. Blot is representative of $n=2$ independent experiments, except for 293-EBNA ECM detected with 
the MAB3074 antibody $(n=6)$. (C) Immunoblotting for TSP-1 fragments in the ECM of HT1080 cells expressing BMP$1(+)$ or E94A $(*)$ with higher antibody concentrations and longer exposition times (non-reducing conditions). Blots are representative of $\mathrm{n}=2$ independent experiments.

Fig. 4. Intact TSP-1 promotes the adhesion of HT1080 cells but cleaved TSP-1 does not. (A) Phase contrast images of parental HT1080 cells transfected with two siRNAs targeting TSP-1 or with a control siRNA $72 \mathrm{~h}$ after transfection. Scale bar, $200 \mu \mathrm{m}$. Extinction efficiency was assessed through the immuno-detection of TSP-1 in cell medium (loading control: collagen VI). Images and blots are representative of $n=4$ and $n=3$ independent experiments respectively. (B) Fluorescence microscopy showing actin (green) and nuclei (blue) in HT1080 cells transfected with the indicated siRNAs and quantification of cell area. Scale bar, $50 \mu \mathrm{m}$. Data are representative of 2 independent experiments and shows means $\pm 95 \%$ confidence intervals from 15 fields per condition and replicate. (C) Percentage of detached cells $72 \mathrm{~h}$ after transfection with the indicated siRNAs. The data show means \pm SD of 4 independent experiments. (D) Adhesion of HT1080 cells on intact and cleaved TSP-1. TSP-1 was incubated for $4 \mathrm{~h}$ with (+) or without (-) recombinant BMP-1 or the inactive E94A mutant $(*)$, at $4^{\circ} \mathrm{C}$ or $37^{\circ} \mathrm{C}$ prior to the assay (conditions 1-4). Control conditions with BMP-1 alone or buffer are also shown (conditions 5-6). The gel is representative of $n=3$ independent experiments and the graph shows means \pm SD of the same experiments (performed in triplicates for each TSP-1 coating concentration). (E) Adhesion of HT1080 cells on TSP-1-coated plates in the presence of increasing concentrations of soluble TSP-1. The graph shows means \pm SD of 3 independent experiments each performed with 3 or 4 technical replicates. Conditions were compared to control using the test of Kruskal-Wallis with Dunn's multiple comparison test. (F) Adhesion of HT1080 cells on TSP-1coated plates in the presence of $157 \mathrm{nM}$ soluble full-length TSP-1, purified fragment 1, or semi-purified fragment 2. The graph shows means \pm SD of 3 independent experiments each performed with 3 or 4 technical replicates. Conditions were compared to control using the test of Kruskal-Wallis with Dunn's multiple comparison test. 
Fig. 5. TSP-1 cleavage enhances TGF- $\beta$ activation in HT1080 cells. (A) Immunoblotting for SMAD2 and phosphorylated SMAD2 (P-SMAD2) in lysates of HT1080 cells treated for 60 min with the indicated combinations of TSP-1 (visible on the Coomassie-stained gel) and BMP-1 or E94A mutant (*). Final TSP-1 concentration in culture medium was $16.4 \mathrm{nM}$. Actin is a loading control. The gel and blots are representative of $\mathrm{n}=3$ independent experiments. (B) Quantitation of P-SMAD2 in treatment groups 1-7, corresponding to the same conditions as in (A). Intensity was normalized relative to total SMAD2 or actin. The data show means \pm SD of 3 independent experiments. (C) Quantitation of luminescence in lysates of HT1080 cells transfected with the TGF- $\beta$ reporter pGL3(CAGA) 9 -Luc for $24 \mathrm{~h}$ and then treated with the same solutions 1-7 as in (A) (final TSP1 concentrations: 14 or $41 \mathrm{nM}$ ) or with $10 \mathrm{ng} / \mathrm{ml}$ TGF- $\beta$ for another $24 \mathrm{~h}$. The data show means \pm SD of 3 independent experiments. (D) Immunoblotting for P-SMAD2 and SMAD2 in lysates of HT1080 cells stimulated for 60 min with $41 \mathrm{nM}$ of full-length TSP-1 (2 different batches indicated as \#1 and \#2) or purified fragment 1 . Blots are representative of 4 independent experiments. (E) Immunoblotting for mature TGF- $\beta$ and the LAP prodomain in 7.1 $\mu \mathrm{g}$ of full-length TSP-1 (two different batches), purified fragment 1 , or with the indicated amounts of recombinant active TGF- $\beta$ under reducing conditions. Blots are representative of 3 independent experiments. (F) Immunoblotting for P-SMAD2 and SMAD2 in lysates of HT1080 cells treated for 60 min with 390 pM final concentration of LTGF- $\beta$ (equimolar to $10 \mathrm{ng} / \mathrm{ml}$ TGF- $\beta$ ). Before cell treatment and dilution in culture medium, LTGF- $\beta$ was incubated alone or with full-length TSP1 or purified fragment 1 (two different batches of each) for 15 min. Blots are representative of 3 independent experiments. (G) Quantification of LTGF- $\beta$ activation by intact and cleaved TSP-1 based on immunoblots obtained as in (F). The graph shows means \pm SD of percentages of maximal LTGF- $\beta$ activation compared to $100 \%$ for acid activation. $\mathrm{n}=3$ independent experiments. Activations with TSP- 1 and fragment 1 were compared using the Student's $t$-test.

Fig. 6. Effect of TSP-1 cleavage on the adhesion of keratocytes. (A) Parental HT1080 cells were seeded in serum-free conditioned medium from HT1080 (a) or HT1080-BMP-1 (b) cells as controls. Images were taken $24 \mathrm{~h}$ after seeding and are representative of $n=2$ independent experiments. Keratocytes were seeded in freshly-collected, serum-free 
conditioned medium of keratocytes (c, d, e) in the absence of any additive (c) or in the presence of vehicle (d) or of 185 $\mathrm{nM}$ recombinant BMP-1 (e) or in serum-free conditioned medium of keratocytes cultivated with $5 \mu \mathrm{M}$ of the BMP-1 inhibitor Hxt (f). Images were taken $6 \mathrm{~h}$ after seeding and are representative of $n=3$ independent experiments. Scale bar, $50 \mu \mathrm{m}$. (B) Immunoblotting for TSP-1 and its proteolytic products in the conditioned medium and ECM of keratocytes cultured in serum-free conditions for $48 \mathrm{~h}$, in the absence or presence of $30 \mu \mathrm{M}$ Hxt or of $300 \mathrm{nM}$ Szl. Blots probed with MAB3074 are representative of $n=4$ (medium) or 3 (ECM) independent experiments, and blots probed with C9 are representative of $n=2$ independent experiments. (C) Immunoblotting for fragment 1 in the supernatants of cells grown in conditions $\mathrm{c}, \mathrm{d}$ and $\mathrm{e}$ at the end of the adhesion experiment described in (A). Blots are representative of $\mathrm{n}=3$ independent experiments. (D) Immunoblotting for endogenous BMP-1 in the conditioned medium of human primary keratocytes under reducing conditions. Medium was collected after $48 \mathrm{~h}$ and concentrated using ultrafiltration. $50 \mathrm{ng}$ of recombinant purified human BMP-1 (recBMP-1) is a control. Blot is representative of $n=2$ independent experiments.

Fig. 7. TSP-1 cleavage potentiates keratocyte differentiation into myofibroblasts. (A) Immunoblotting for phosphorylated SMAD2 (P-SMAD2) and SMAD2 in cell lysates of keratocytes treated for 30 min with intact and cleaved TSP-1 (41 nM final concentration) or $10 \mathrm{ng} / \mathrm{ml}$ TGF- $\beta$. Actin is a loading control. Blots are representative of $\mathrm{n}=3$ independent experiments. (B) Quantitation of P-SMAD2 in the same conditions as in (A). Intensity was normalized relative to total SMAD2 and actin. Graph shows means \pm SD of $n=3$ independent experiments. (C) Staining for $\alpha$-SMA in primary keratocytes maintained for $72 \mathrm{~h}$ in serum-free medium under the same treatment conditions $1-4$ as in (A) or with $10 \mathrm{ng} / \mathrm{ml}$ TGF- $\beta$. Scale bar, $100 \mu \mathrm{m}$. Images are representative of $\mathrm{n}=2$ independent experiments. (D) Quantitation of cells with $\alpha$-SMA fibers. Box plot shows data from 20 images/condition from 2 independent experiments. All conditions were compared using two-way ANOVA and Tukey post-ANOVA test. 
Fig. 8. TSP-1 processing may play a role in corneal wound healing. (A) Immunoblotting for TSP-1 fragment 1 under non-reducing conditions using MAB3074 in lysates of $n=4$ corneas from patients with permanent corneal scars.

Volumes of corneal lysates loaded in each lane were adjusted to equivalent total protein amounts. Various amounts of keratocyte conditioned medium (CM) corresponding to $0.2-1.5 \mu \mathrm{g}$ total protein were also loaded on the gel to facilitate the identification of fragment 1 in the human samples. Before detection, the membrane was split into 2 parts, and two different exposure times were used to reveal intact TSP-1 and fragment 1 . Blot is representative of 3 technical replicates using the same samples. (B) Schematic representation of the ex vivo murine cornea wound healing experiments. (C) Micrographs of the corneas taken at day $1(\mathrm{~d} 1), \mathrm{d} 4$, and $\mathrm{d} 7$ after healing in the presence of vehicle (condition 1), intact TSP-1 (condition 2), BMP-1 (condition 3), cleaved TSP-1 (condition 4), cleaved TSP-1 plus the TGF- $\beta$ type I receptor inhibitor SB431542 (condition 5), or TGF- $\beta$ (condition 6). Scale bar, $500 \mu \mathrm{m}$. Images are representative of $\mathrm{n}=8-9$ corneas per condition except for condition $5(n=5)$. (D) Evolution of wound contraction measured over time presented as $\%$ of initial wound area. The graph shows means \pm SD of $n=5$ corneas for condition 5 and $n=8-9$ corneas for other conditions. Condition 4 was compared to other conditions using one-way ANOVA and Dunnett's multiple comparison test. (E) Immunofluorescence showing $\alpha$-SMA (red) at the wound borders at the end of the experiment. Nuclei are labelled with DAPI (blue). Tissue sections were localized as shown with dashed arrows in (C). A full view of a cornea treated with vehicle is shown in the upper panel with the wound (w) marked. Examples of regions used to count myofibroblasts are shown below for each condition. Scale bar, $100 \mu \mathrm{m}$. Images are representative of $\mathrm{n}=8-9$ corneas per condition for conditions 1-4, $n=5$ corneas for condition 5 and $n=6$ corneas for condition 6. (F) Quantification of $\alpha$ SMA-positive cells in the same wounded corneas. The data show the percentages of cells at the wound border that myofibroblasts in each condition expressed as means \pm SD (cornea numbers as in (E); 3-4 fields per cornea were used for quantification).

Fig. 9. TSP-1 is at the crossroads of two main pathways regulated by BMP-1, cell-matrix interactions and growth factor signaling. BMP-1 promotes cell-dependent effects on adhesion and TGF- $\beta$ activity. In turn, TGF- $\beta$ signaling can 
increase BMP-1 expression and regulate immune responses, ECM synthesis, and wound contraction during wound healing. The effect of TSP-1 processing on collagen fibrillogenesis and angiogenesis remains to be explored. SLRP, small leucine-rich proteoglycan. 
A empty vector BMP-1 vector B

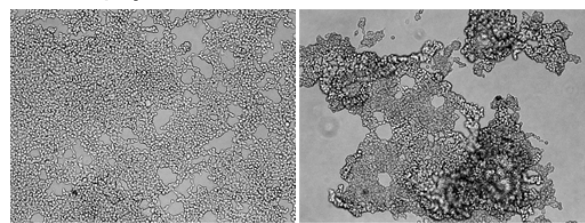

BMP-1 vector + Hxt

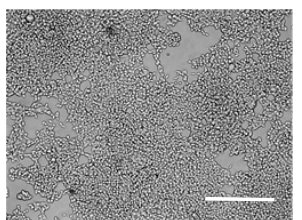

D
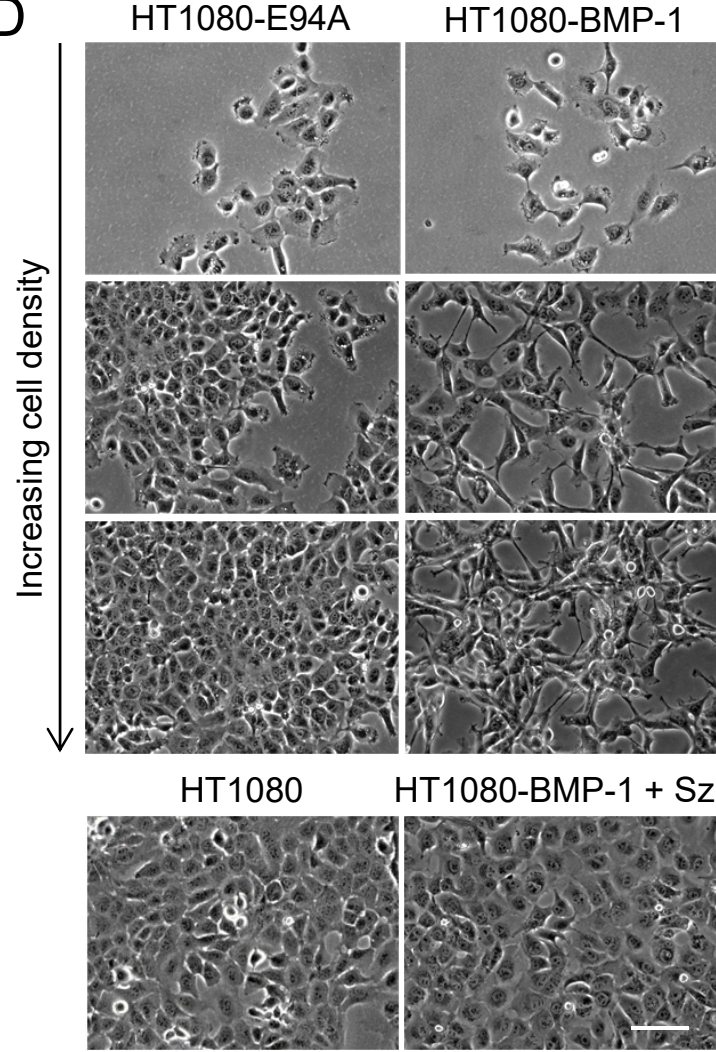

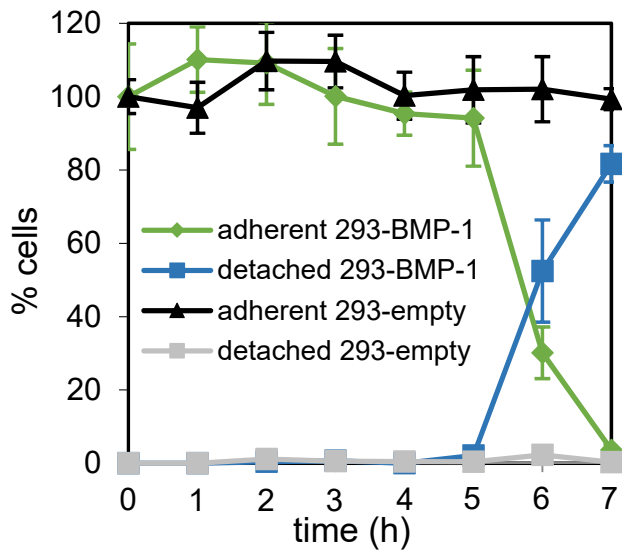

$E$
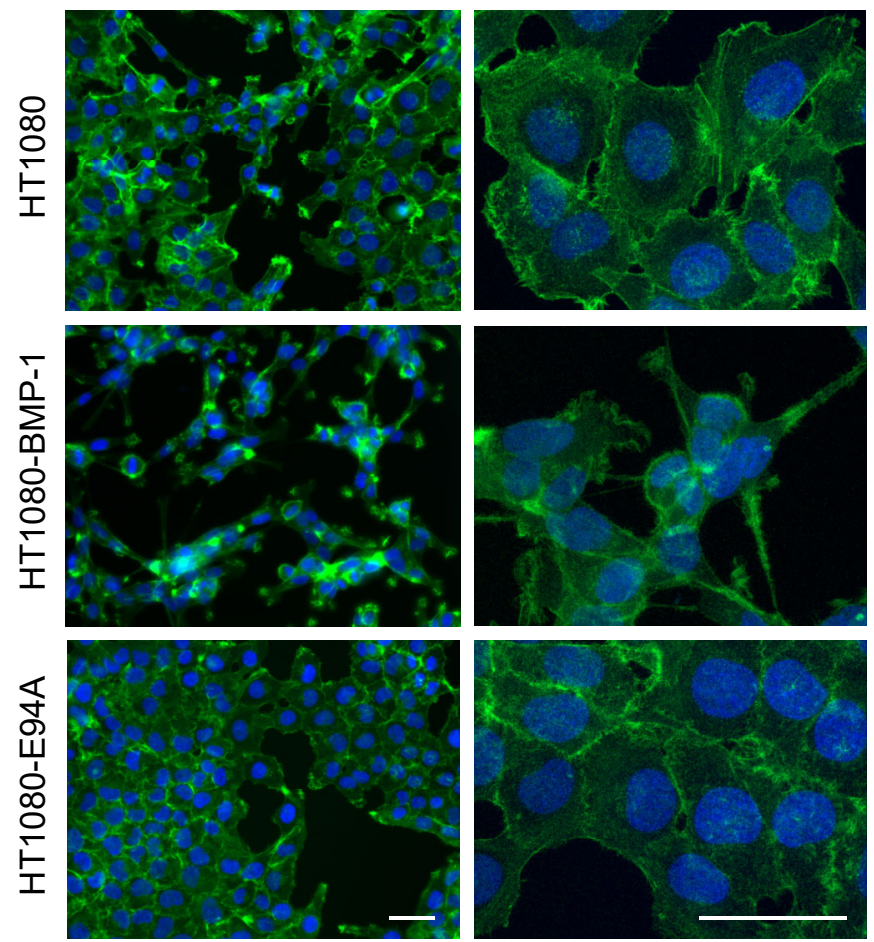

$\mathrm{H}$

HT1080 ECM

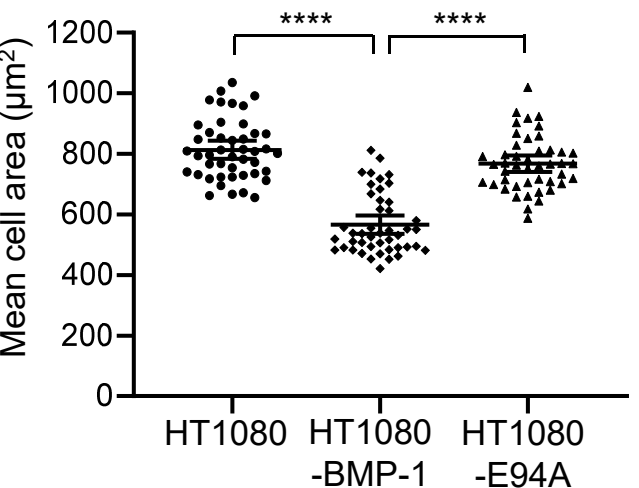

G

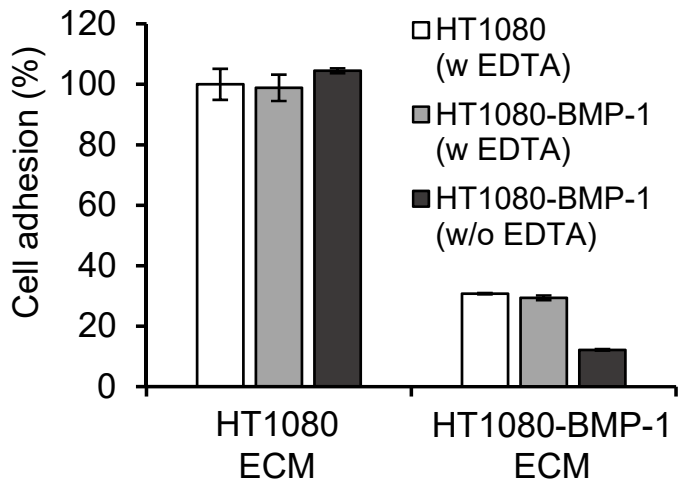

\section{G}

ECM
$\mathcal{C}$

vector

empty BMP-1
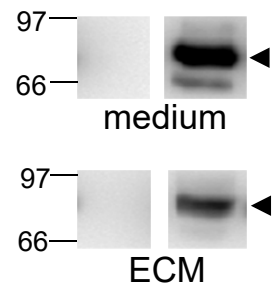

है

$\mathrm{F}$

BMP-1 -E94A

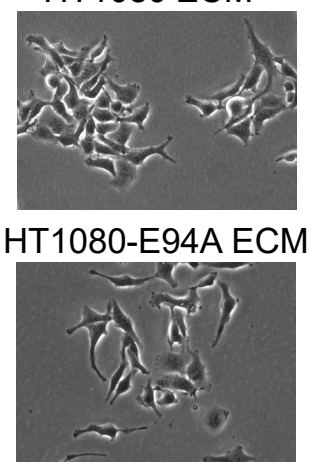

HT1080-BMP-1 ECM

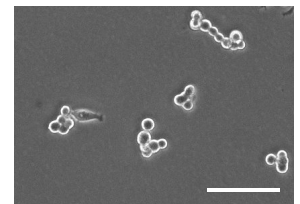


A

MAB3074

\section{0}

BM
4 TSP-1

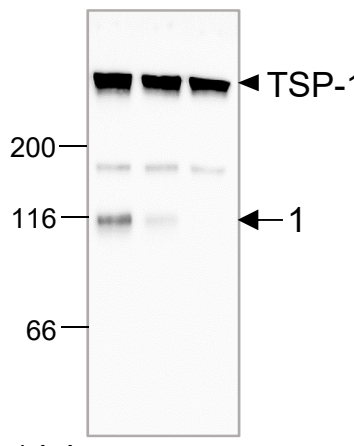

HT1080-BMP-1 HT1080 medium
BMP-1 inh. - + ++

medium

$\leftarrow 1$

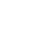

(n)

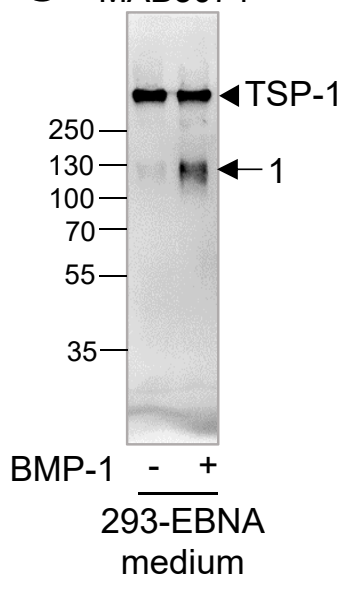

D

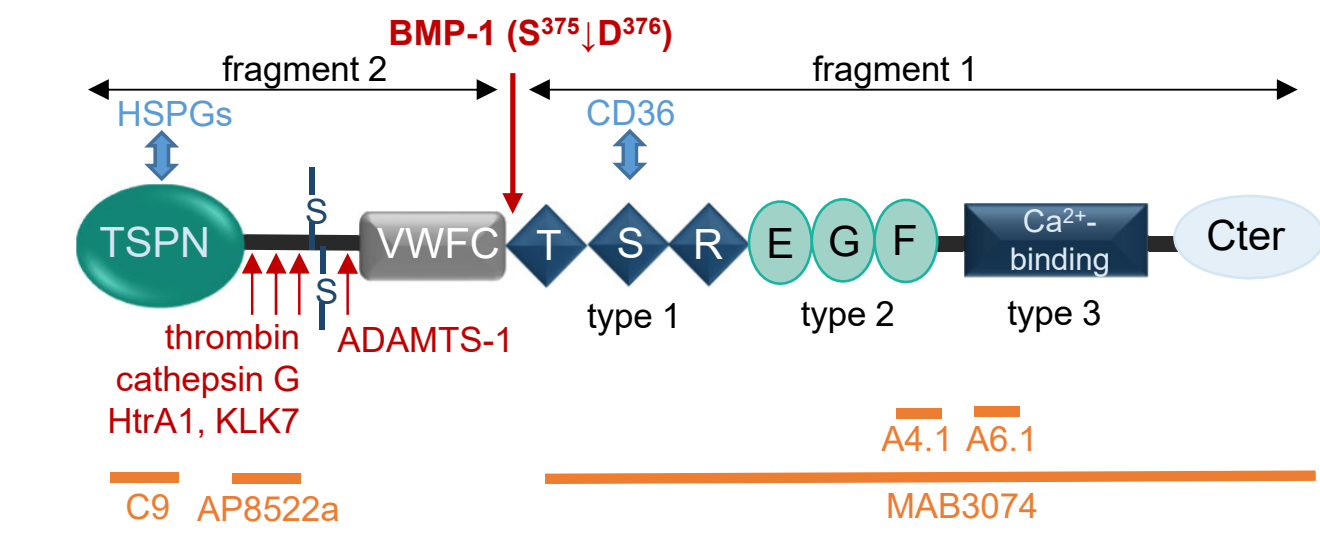

E

E
$\mathrm{t}$ (h) $4 \quad 4 \quad 4 \quad 4 \quad 4$
$\begin{array}{llll}8 & 2 & 4 & 8\end{array}$

BMP-1:TSP-1 0 1:10 1:4 1:1
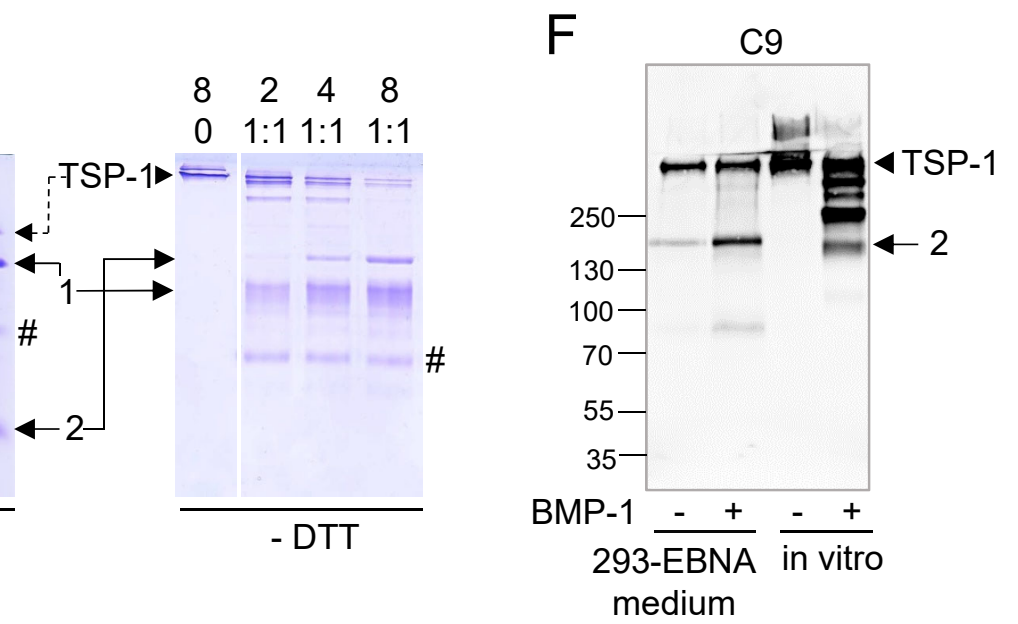


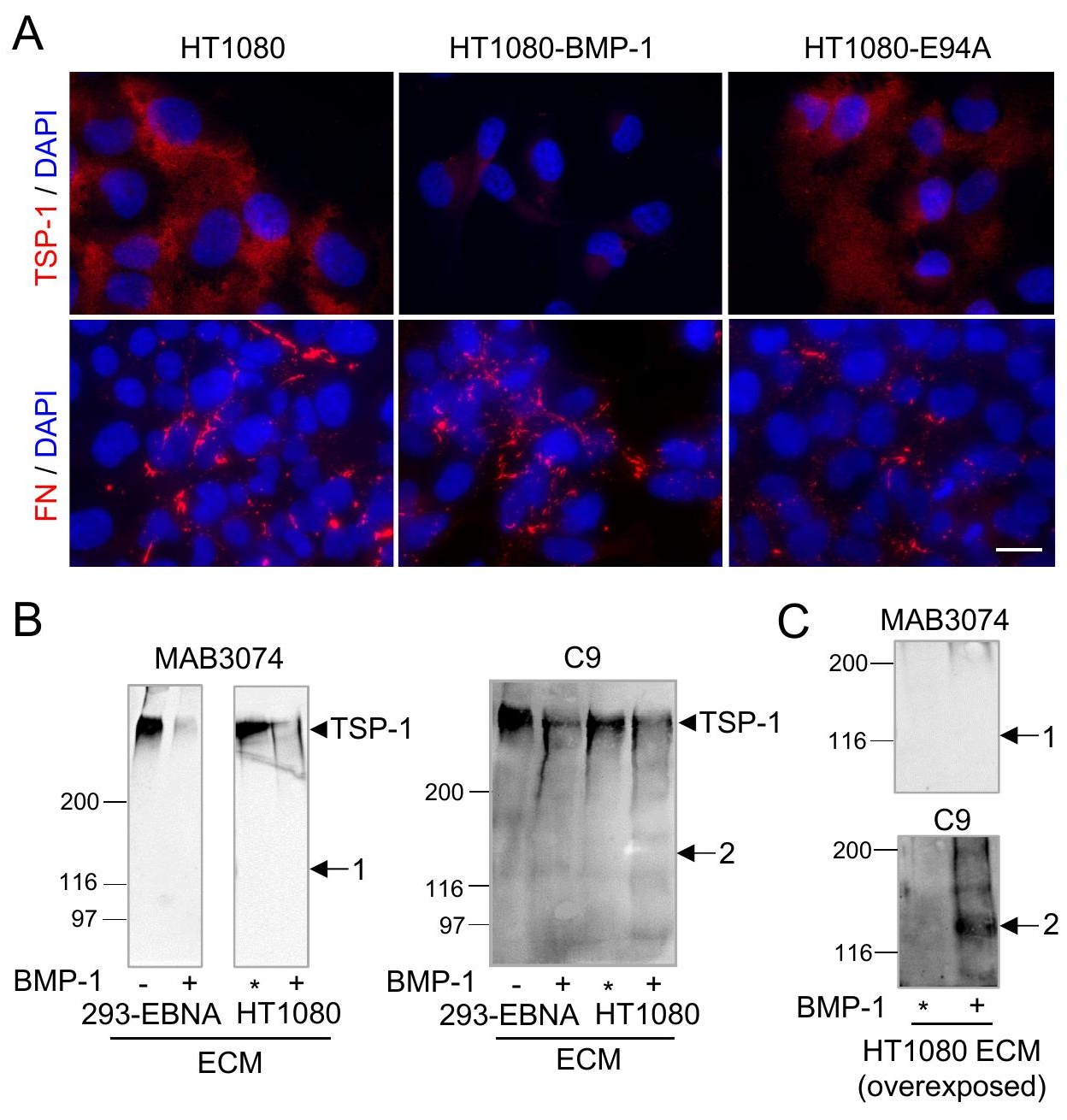


A
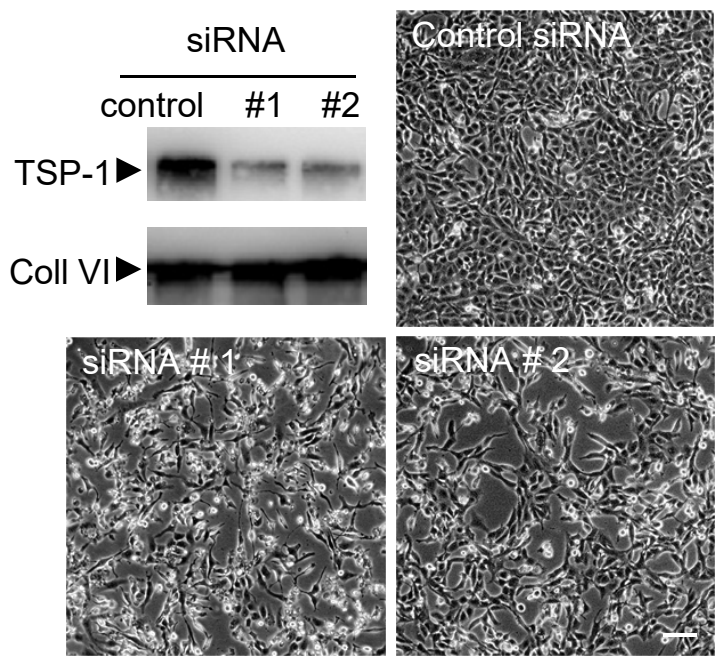

B
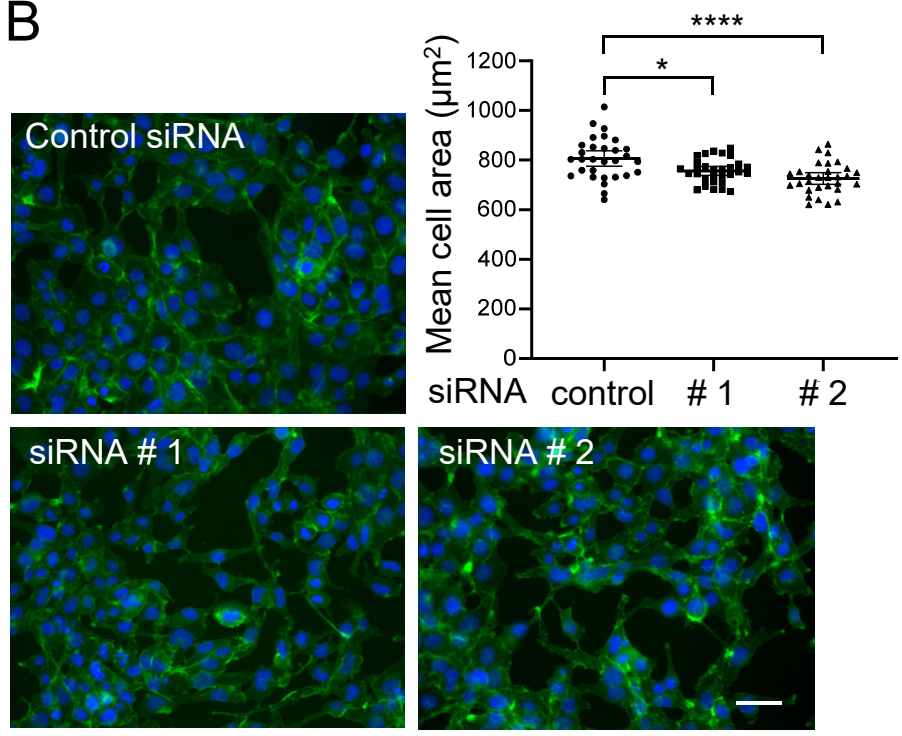

C

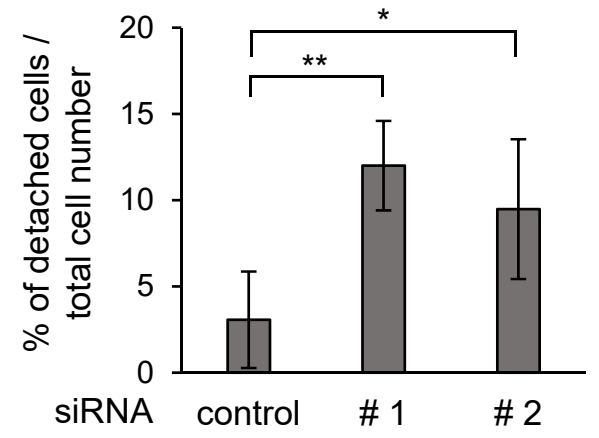

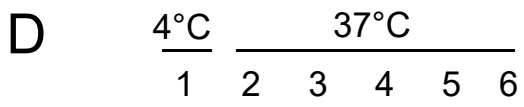

TSP-1 ++++-

BMP-1 - - * + +

200-

TSP-1

$116-$

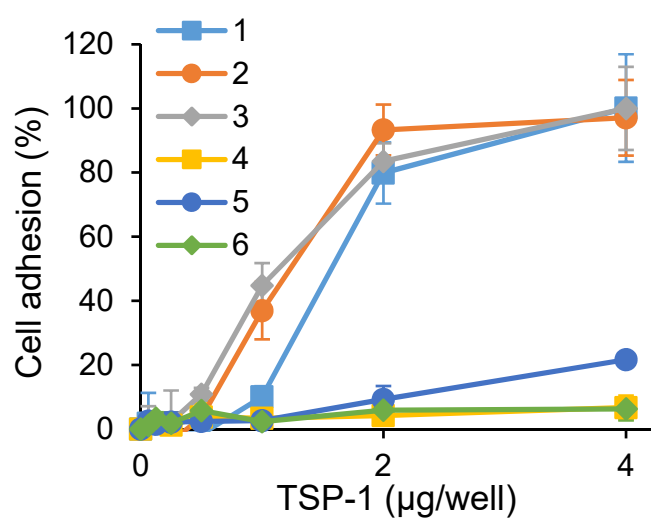

E
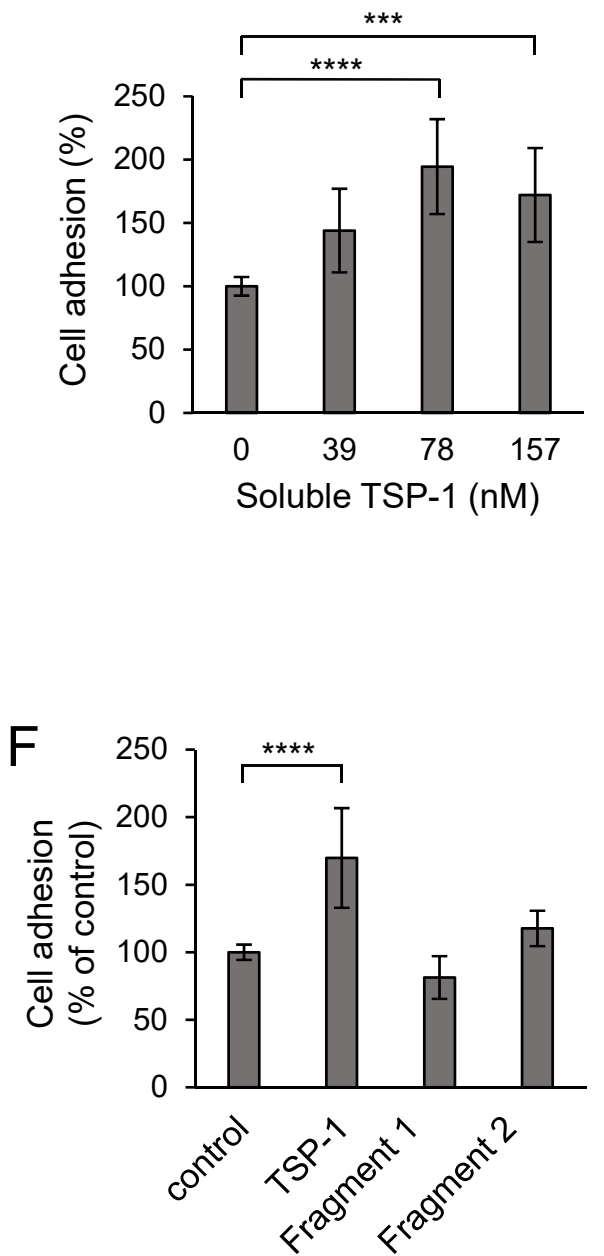
A

$\frac{\mathrm{Oh}}{1}$\begin{tabular}{cccccc}
\multicolumn{7}{c}{$4 \mathrm{~h}$} \\
\hline 2 & 3 & 4 & 5 & 6 & 7
\end{tabular}

TSP-1 +++-+-

$\mathrm{BMP}-1-\quad++* *-$
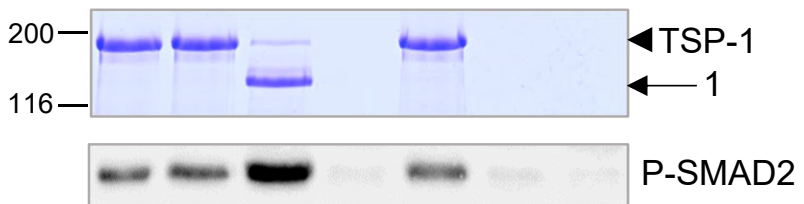

SMAD2

B

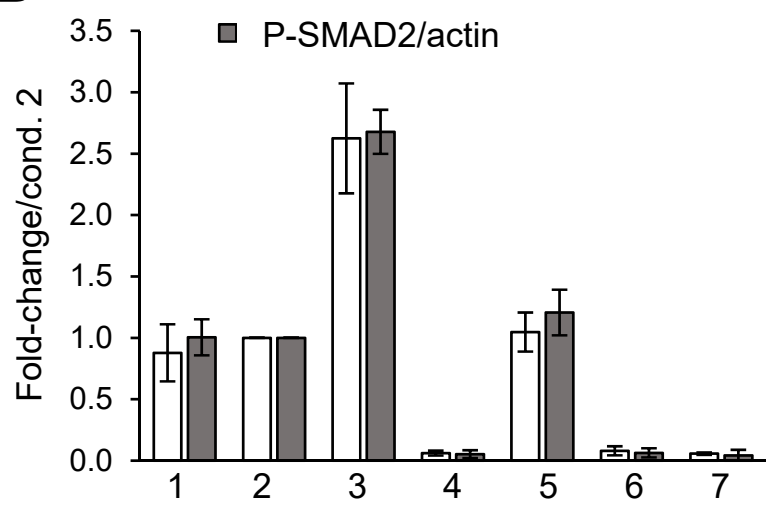

$\mathrm{C}$

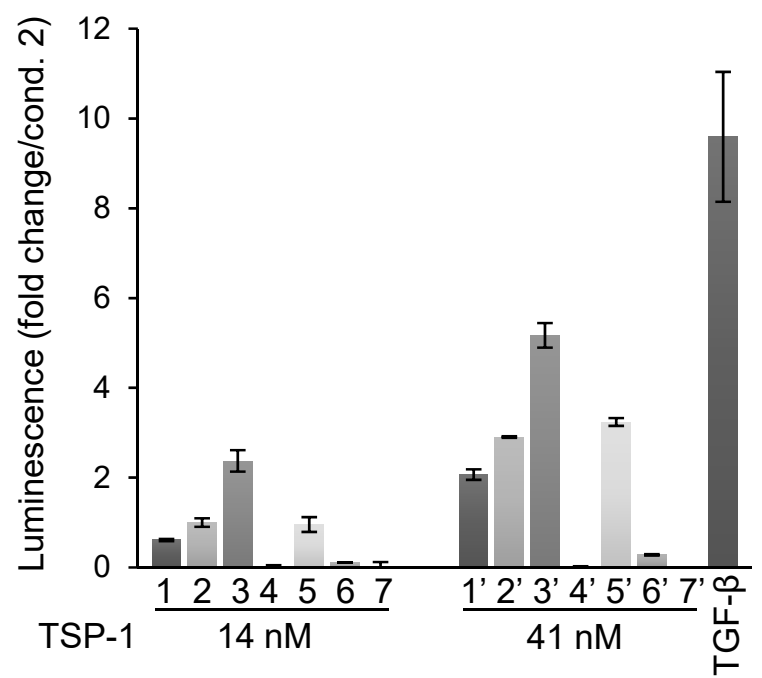

D

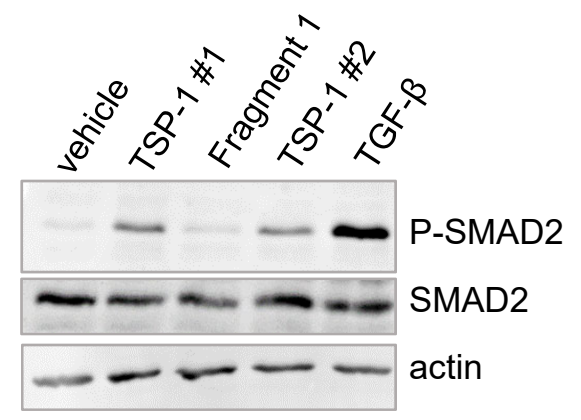

E
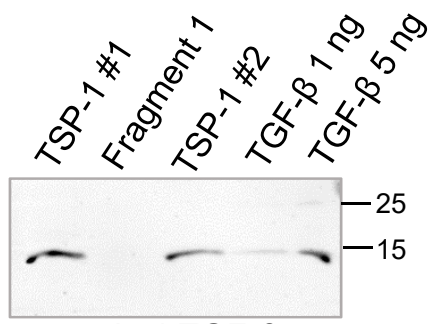

Anti-TGF- $\beta$

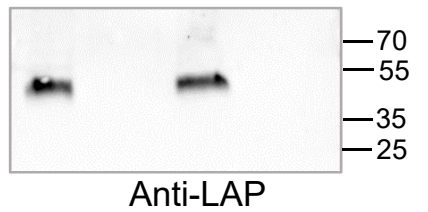

F
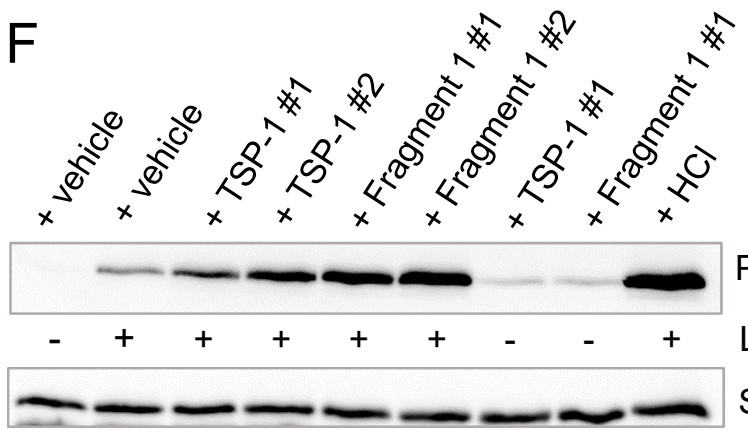

P-SMAD2

LTGF- $\beta$

SMAD2

actin

G

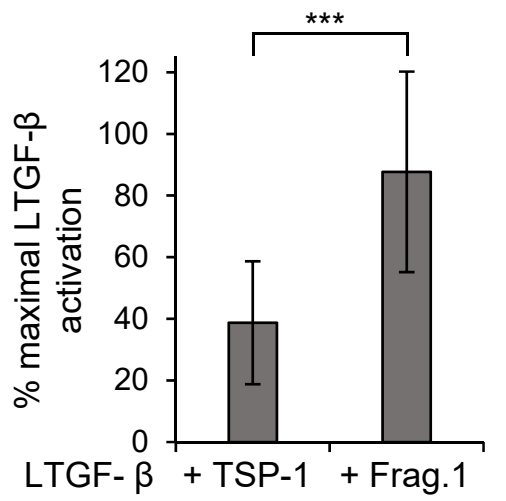


A
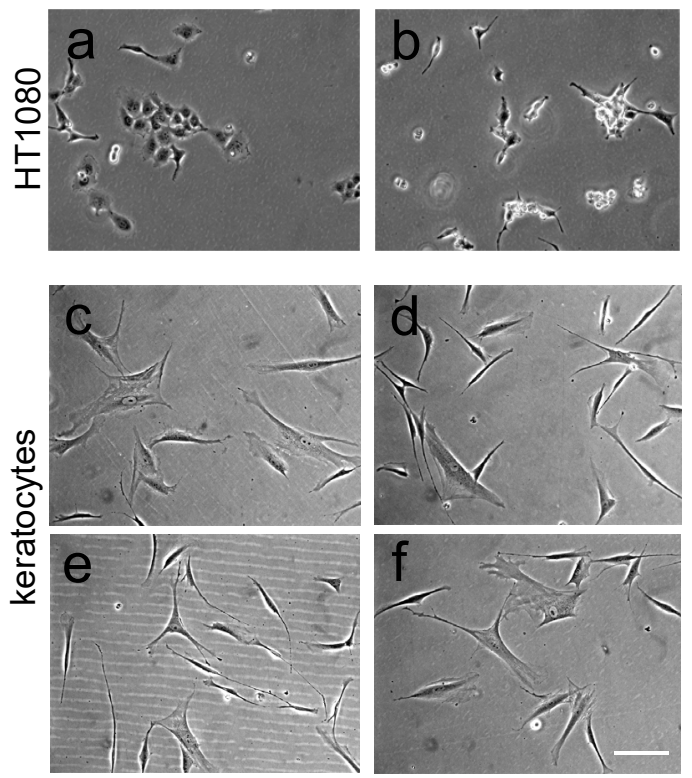

C

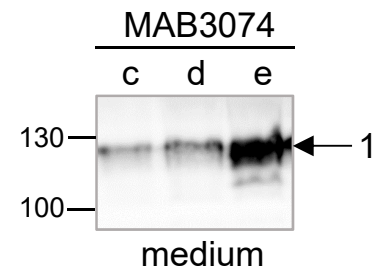

B
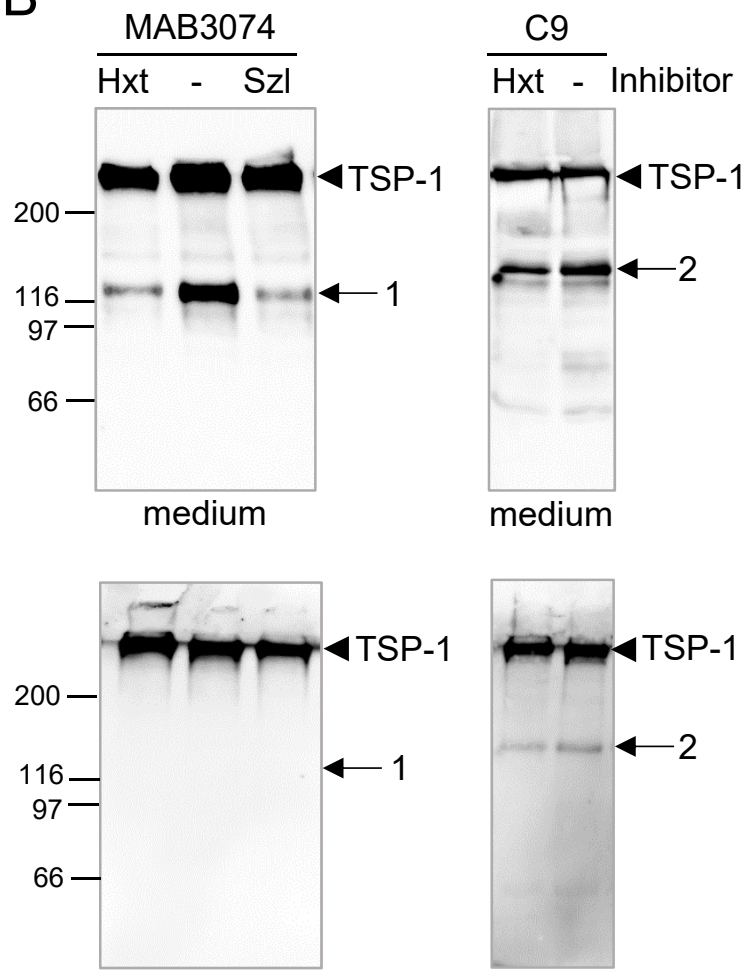

ECM

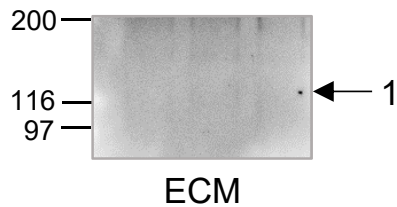

overexposed

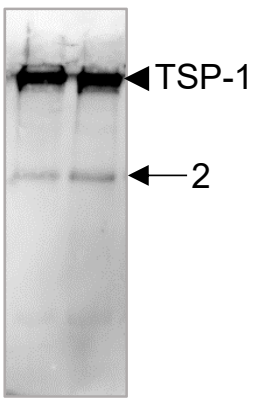

ECM

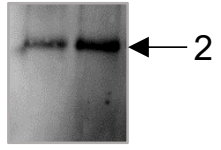

ECM overexposed 
A

$\begin{array}{rrrrrr}1 & 2 & 3 & 4 \\ \mathrm{TSP}-1 & + & + & - & - \\ \mathrm{BMP}-1 & - & + & + & - & \mathrm{K}^{\mathrm{S}}\end{array}$

$-\infty-\ldots$ P-SMAD2

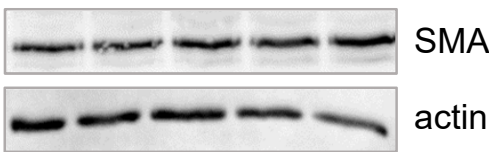

B

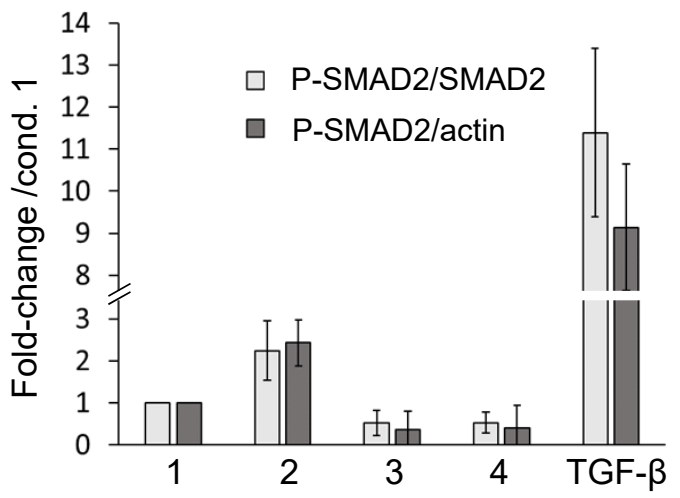

C

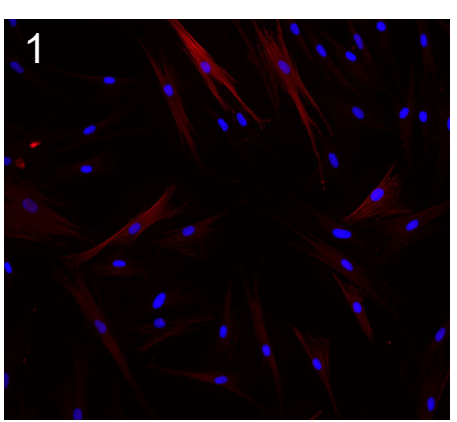

3

D

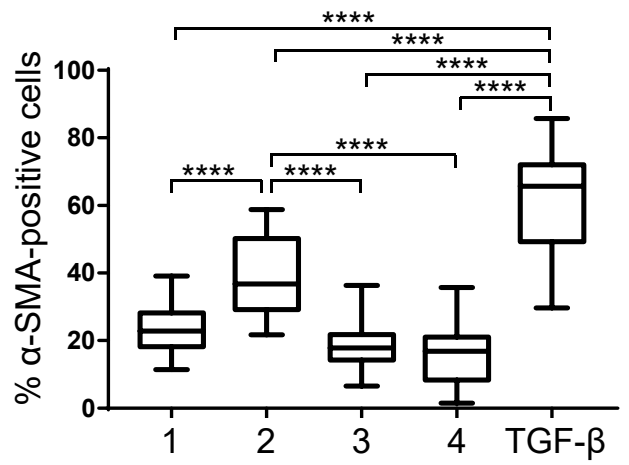


kerat. $x^{2} x^{3}$ kerat.

medium $e^{2}$ is

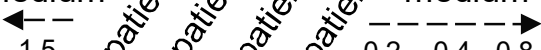

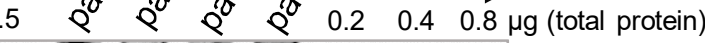

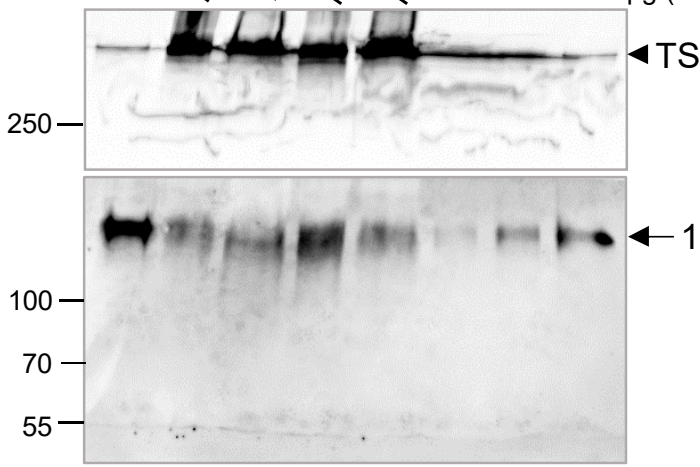

Patient 1 Patient 4

SP-1
B

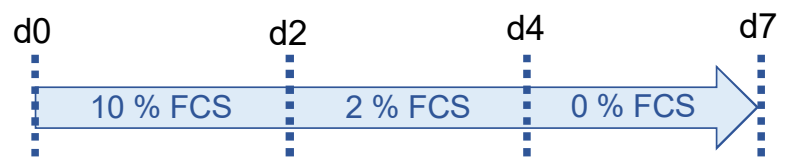

\section{Cornea dissection Medium \\ Medium \\ Paraffin}

+ wound $=$

renewal

start of ex vivo + TSP1/TGF- $\beta$ + TSP $1 /$ TGF $-\beta$ culture

C

1. vehicle

2. TSP-1

(intact)

3. BMP-1
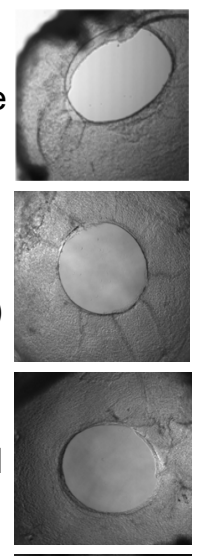

4. TSP-1

(cleaved)

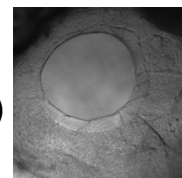

5. TSP-1 (cleaved) + SB431542

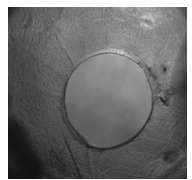

6. TGF- $\beta$ renewal d4
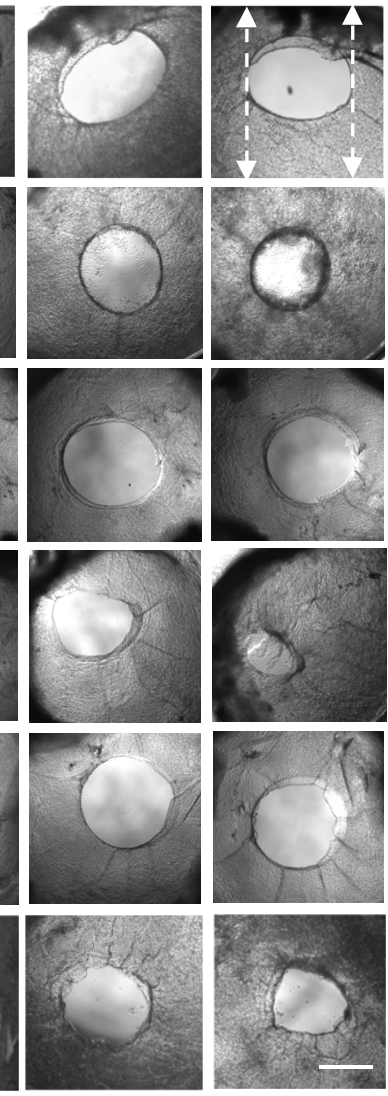
embedding and IF

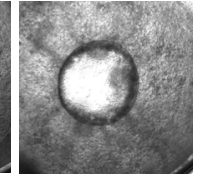

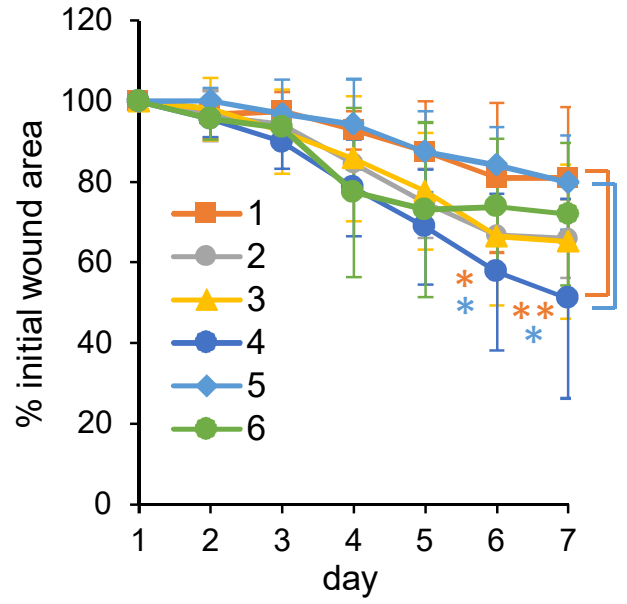

E
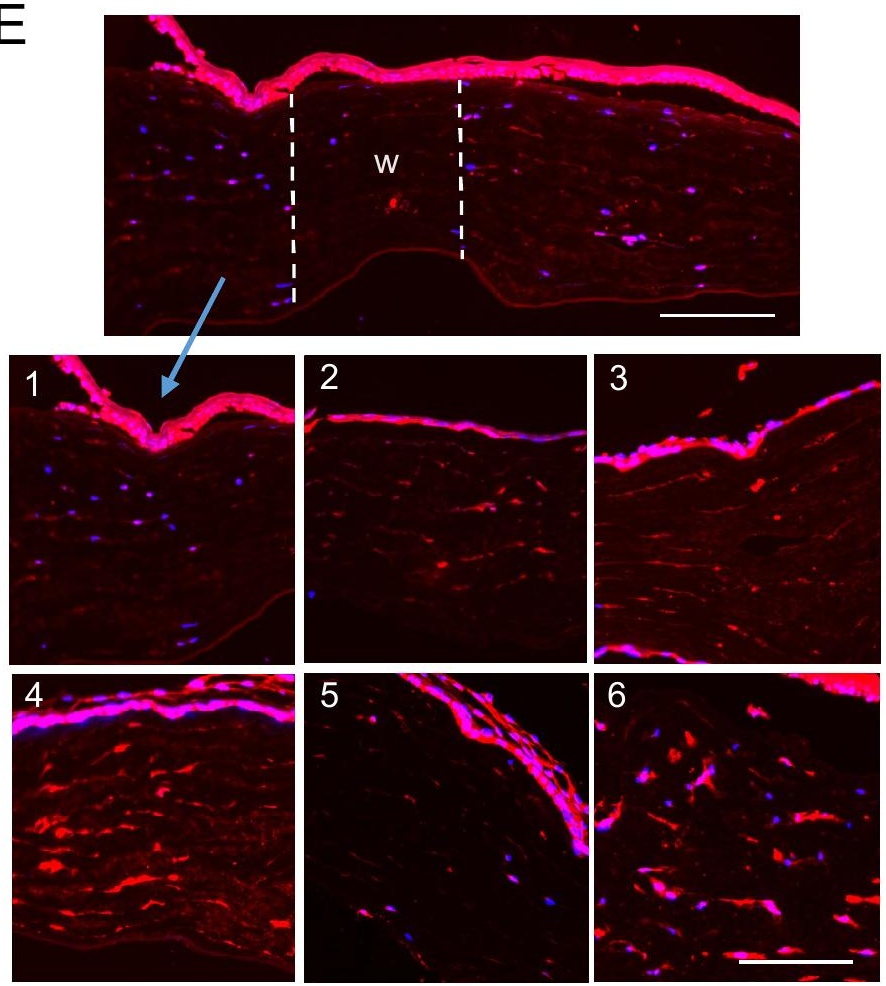

$\mathrm{F}$

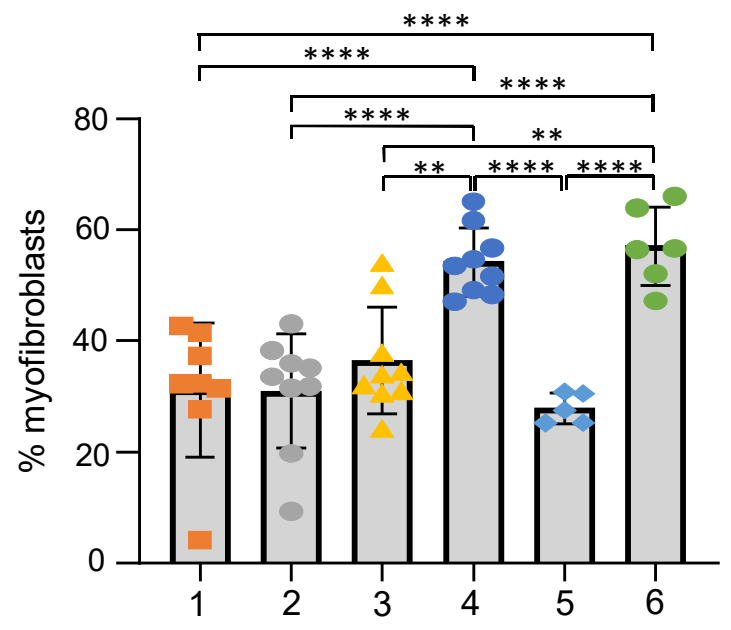




\section{Po BMP-1}

$\oplus$

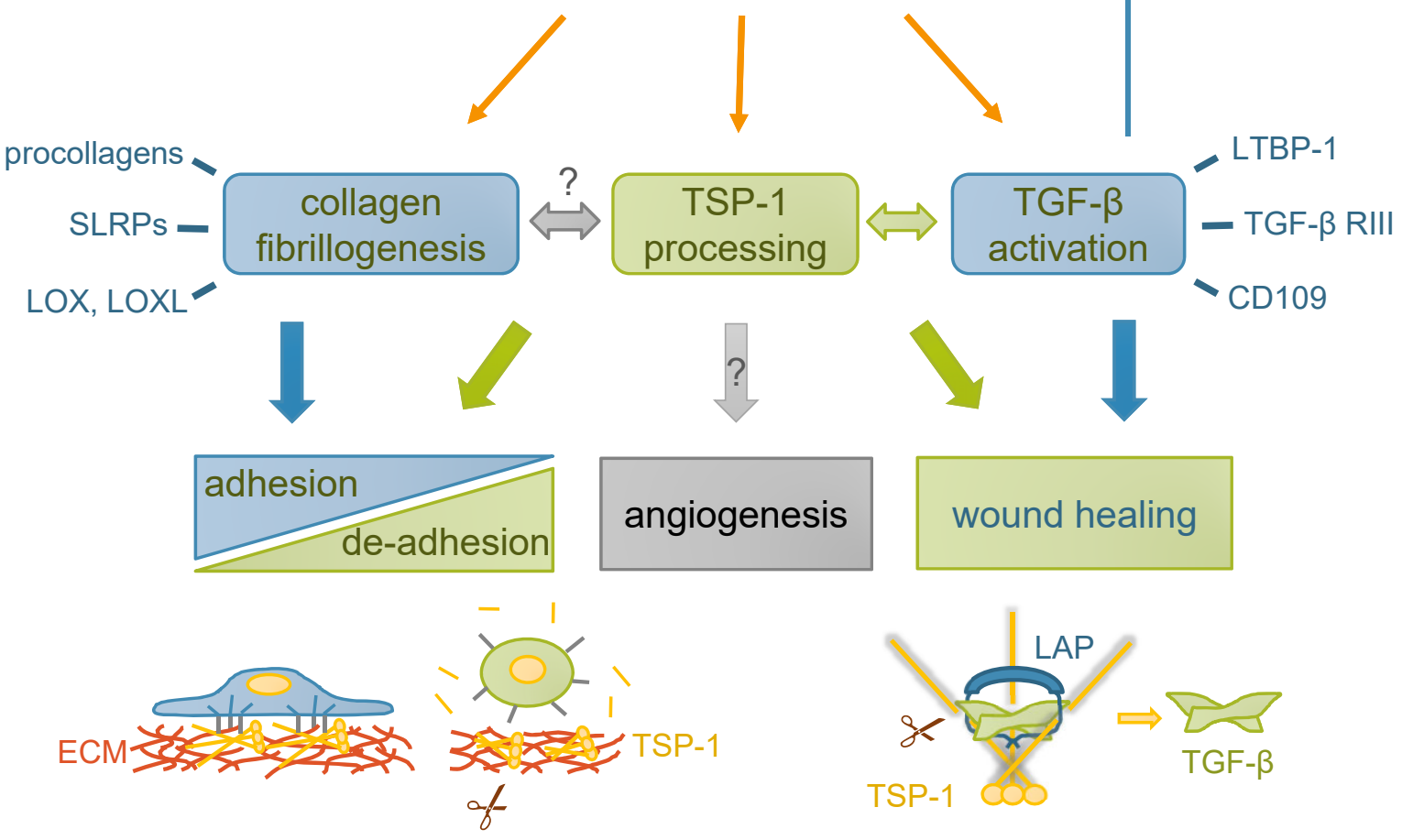

